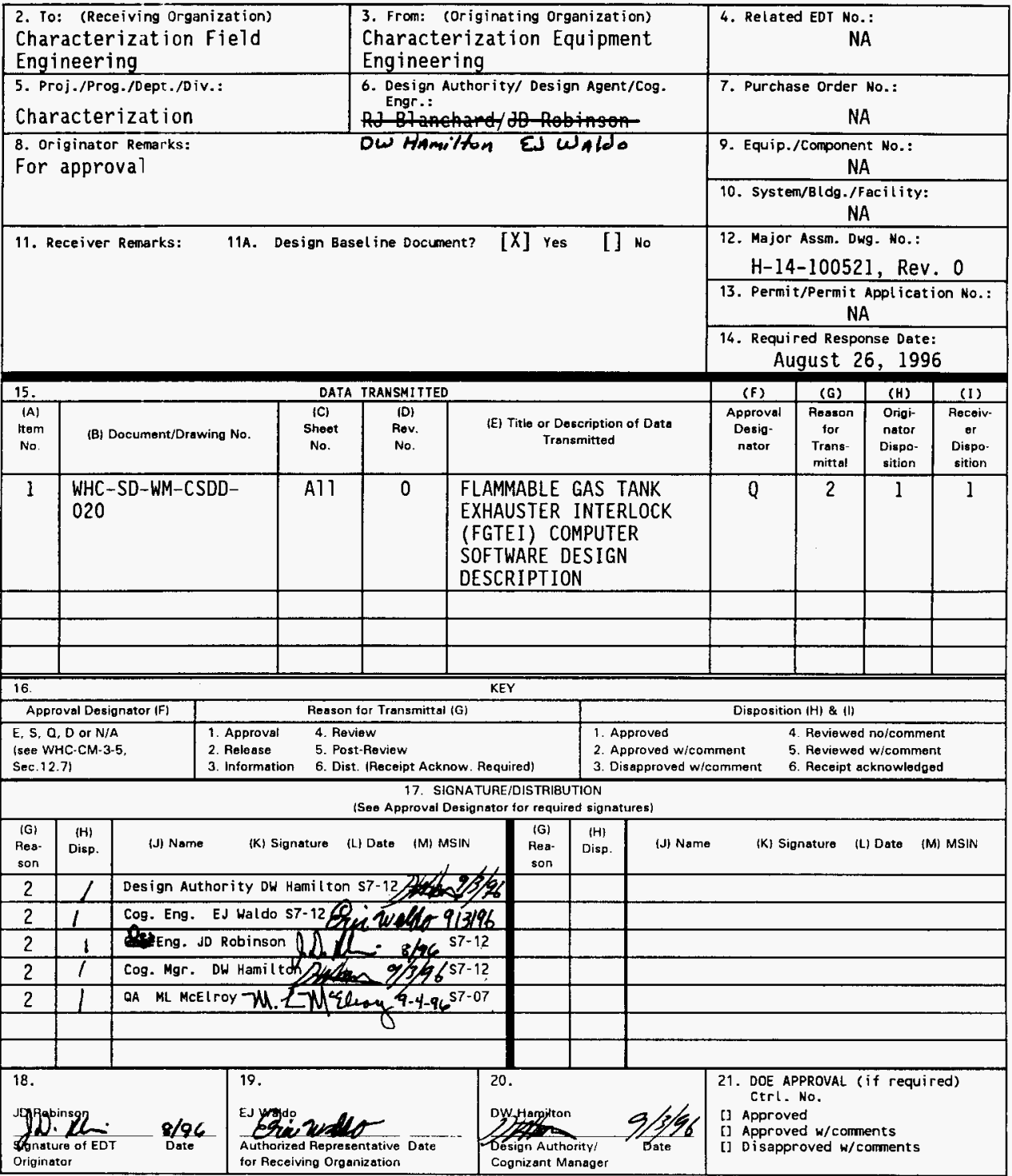




\section{FLAMMABLE GAS TANK EXHAUSTER INTERLOCK (FGTEI) COMPUTER SOFTWARE DESIGN DESCRIPTION}

So Smith/RW Truitt

Westinghouse Hanford Company, Richland, WA 99352

U.S. Department of Energy Contract DE-AC06-87RL10930

615408

EDT/ECN: 615777

Org Code: 75230

B\&R Code: EW3120074

UC: 2070

Charge Code: NAHBB

Total Pages: 66

Key Words: Flammable gas tank exhauster interlock, (FGTEI), software design.

Abstract: Modicon Compact Programmable Logic Controller (PLC). The device configuration integrates the isolation and currentcarrying capacities of mechanical relays with the logic and programming sophistication of the PLC.

This document provides descriptions of components and tasks involved in the PLC system for controlling and monitoring the FGTEI. All control functions required by the PLC, and how they are implemented, are described in detail.

Modicon is a Registered Trademark of Modicon, Inc.

TRADEMARK DISCLAIMER. Reference herein to any specific commercial product, process, or service by trade name, trademark, manufacturer, or otherwise, does not necessarily constitute or imply its endorsement, recommendation, or favoring by the United States Government or any agency thereof or its contractors or subcontractors.

Printed in the United States of America. Io obtain copies of this document, contact: WHC/BCS Document Control Services, P.O. Box 1970, Mailstop H6-08, Richland WA 99352, Phone (509) 372-2420; Fax (509) 376-4989.
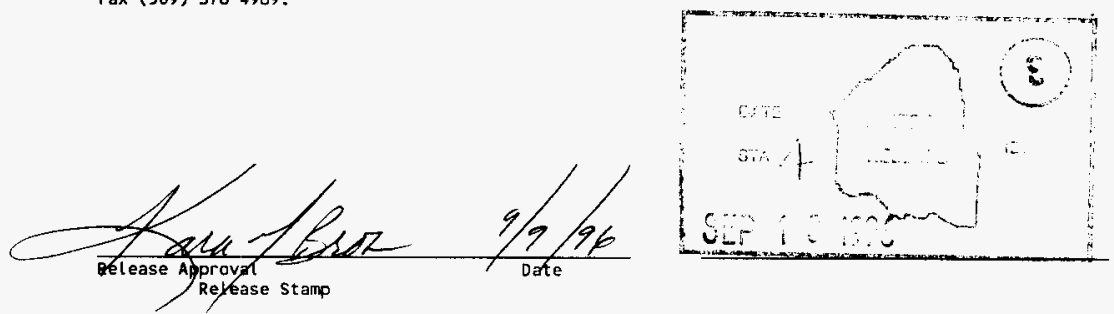

\section{Approved for Public Release}


WHC-SD-WM-CSDD-020, REV 0

\section{FLAMMABLE GAS TANK EXHAUSTER INTERLOCK (FGTEI) COMPUTER SOFTWARE DESIGN DESCRIPTION}

August 30,1996

Samuel 0. Smith

Ross W. Truitt

PLCs Plus

for

WESTINGHOUSE HANFORD COMPANY 


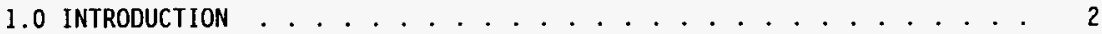

2.0 HARDWARE CONFIGURATION ................... 2

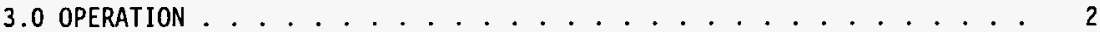

3.1 GENERAL ..................... . . 2

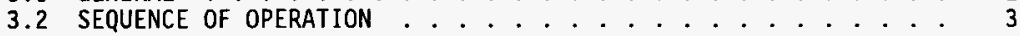

4.0 PLC SOFTWARE DESCRIPTION .................. 9

4.1 GENERAL . . . . . . . . . . . . . 9

4.2 LADDER LOGIC NETWORK DESCRIPTIONS $\ldots . . . . . . . . . . .99$

APPENDIX A . . . . . . . . . . . . . . 22

I/0 Channe1 List . . . . . . . . . . . . . . 22

APPENDIX B ..................... . . 26

Reference Symbol Table ................ 26

APPENDIX C .............................. 31

PLC System Configuration ............. 31

APPENDIX D . . . . . . . . . . . . . . . . . . . . . . . 34

Ladder logic Network Diagrams............. 34

APPENDIX E ........................ 49

Coil/Register Utilization Tables ........... 49

APPENDIX $F \ldots \ldots 63$

ADU206 Control Register Reference . . . . . . . 63 
WHC-SD-WM-CSDD-020, REV 0

FLAMMABLE GAS TANK EXHAUSTER INTERLOCK (FGTEI)

COMPUTER SOFTWARE DESIGN DESCRIPTION

\subsection{INTRODUCTION}

The Flammable Gas Tank Exhauster Interlock (FGTEI) is controlled by a Modicon Compact Programmable Logic Controller (PLC). The device configuration integrates the isolation and current-carrying capacities of mechanical relays with the logic and programing sophistication of the PLC.

This document provides descriptions of components and tasks involved in the PLC system for controlling and monitoring the FGTEI. All control

functions required by the $\mathrm{PLC}$, and how they are implemented, are described in detail.

\subsection{HARDWARE CONFIGURATION}

As shown on drawings $\mathrm{H}-14-100519$ and $\mathrm{H}-14-100520$, the FGTEI PLC system is comprised of the following:

- 2 backplane housings (HDTA-200 and HDTA 201)

- l controller module (A984-145)

- 2 power supplies (P120)

- 1 l20 VAC 16-channel discrete input module (DEP218)

- 2120 VAC 16-channel discrete output modules (DAP218)

- 2 4-20 mA 4-channel analog input modules (ADU206)

Appendix A lists the specific backplane 1/0 slots for each module.

Each component has been carefully chosen, based on its capabilities, to perform a specific task. The system is designed to collect data from external inputs and sensors, and perform programmed control tasks based on specified input criteria. The external FGTEI logic, using hard-wired relays, works in concert with the PLC ladder logic to provide safe operation of the portable exhauster.

\subsection{OPERATION}

\subsection{GENERAL}

The primary purpose of the FGTEI is to trip the interlock to the Rotary Mode Core Sampling (RMCS) truck if any abort limits have been exceeded. These 
RMCS abort signals include the following:

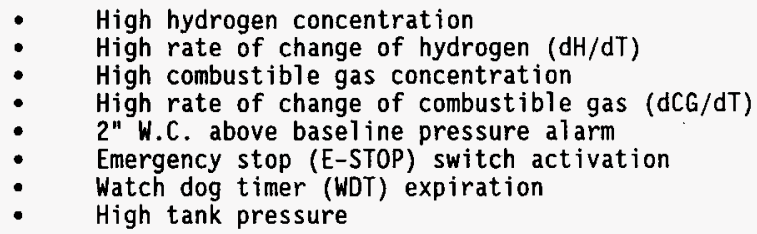

In addition, the FGTEI wi1l also shut down the portable exhauster should the pressure drop below -3" W.C., or if the tank pressure instrument fails.

The FGTEI samples gas from the respective tank from a spoolpiece installed between the tank exhaust header and the portable exhauster.

Continuity of the truck shut down circuit is interrupted by normally open relay contact located on the exhauster. Power to the exhauster is interrupted by a motor contactor located in each FGTEI unit. Two FGTEI units are provided for redundancy and are controlled independently by their respective PLCs.

The "RMCS truck enable" relay contact is closed when conditions are within specified tolerances. The portable exhauster is controlled with the use of a maintained arming circuit, energized by an electro-mechanical relay, enabled by the PLC. When a shutdown condition occurs, the PLC or operator (via the emergency stop button), can trip the circuit and de-energize the A.C. power to the portable exhauster.

\subsection{SEQUENCE OF OPERATION}

NOTE: For the following discussion, reference drawings $\mathrm{H}-14-100519$ and H-14-100520 are necessary.

\section{2.l Analog Input Signals}

Five 4-20 mA signals are connected to the FGTEI. The signals are:

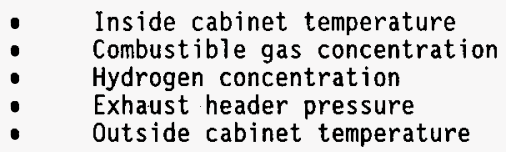

The first four signals are connected to the ADU206 module in slot 7 , with the last signal connected to the ADU206 module in slot 8 . Three channels are available for future use. These are the only analog input signals 
WHC-SD-WM-CSDD-020, REV 0

provided to the PLC system.

\subsubsection{Power Initialization}

The system is started by the operator action of closing the disconnects, energizing the units. The LOSS OF POWER relay coil (K1) is initially energized, closing two normally-open (N.O.) relay contacts, energizing the conditioned control power circuit. The power initialization energizes all major components. This includes the following devices:

- Cabinet air conditioning $(A / C)$ unit

- Inside and outside utility power receptacles

- Control power conditioning unit

- Transducer signal conditioning/transmitters

- Modicon PLC system

As soon as the PLC receives power, an automatic initialization sequence is started. However, if the cabinet temperature is below the operating temperature of the PLC, it will not function. The cabinet will be required to attain a minimum operating temperature, initiated by the EXH FAN START PERMISSIVE button, as described in the following section.

When the PLC starts operation at power-up it begins to control the cabinet temperature to the pre-determined temperature range by actuation of AIR CONDITIONER relay coil (K7) and HEATER relay coil (K8).

The actual temperature of the cabinet is being read by the PLC from a 4-20 mA INSIDE CABINET TEMPERATURE signal being generated from the temperature transmitter. The PLC then commands a heating or cooling action, as required, to maintain the programmed temperature.

If the FGWL (Flammable Gas Watch List) enable input (slot 4, input 7) is sensed, the WATCH DOG timer output is pulsed by the PLC every second. This input verifies that the correct jumper is in place in the external cable, ensuring correct system configuration (see reference drawings). The tank pressure instrument must also be connected and the PLC must measure greater than $2 \mathrm{~mA}$ on the input to enable the watch dog timer. This causes the SYSTEM OK lamp to flash on and off continuously. A programmable time delay relay (VTP-HM-2205/6) requires a pulse to be sent at least every 2 seconds. If the PLC fails, this time delay relay will shut off power to the exhauster by deenergizing the ENABLE POWER TO EXHAUSTER relay coil (K3).

\subsubsection{Start}

NOTE: Previous shutdown conditions may be indicated on the operator's console. These lights are latched on, and will not extinguish until the KEYSWITCH is turned off and back on (see 3.2.4). 
The sequence is initiated by the operators depressing the EXH FAN START PERMISSIVE(S3) button on each unit. The action energizes the HEATER BYPASS relay coil (K2) and energizes the cabinet heater. The CABINET TEMPERATURE OUT OF RANGE lamp is illuminated by a N.O. contact from the parallel HEATER BYPASS relay coil (K12). Since the disconnects have been previously closed, the PLC is on-line and running its ladder logic program. When the PLC senses the HEATER BYPASS N.0. relay contact closure $(K 2)$ on, signifying that the HEATER BYPASS relay coil (K2) has been energized, the PLC de-energizes the HEATER BYPASS relay coil (K2) by toggling the HEATER OFF relay coil (K4) on and off. If the PLC is below operating temperature, the HEATER OFF relay coil (K4) will not be toggled until the PLC has warmed sufficiently to begin operation.

If the FGWL Enable input is on (enabling the WDT contact) then the ENABLE POWER TO EXHAUSTER relay coil (K3) is energized and maintained (latched). The N.0. relay contact closure (K3) is closed, and if all required conditions are met in the PLC, the PLC energizes the MOTOR STARTER relay coil (K6), providing power to the exhauster by energizing the POWER CONTACTOR relay coil (MS). Additionally, the PLC will enable the RMCS truck interlock if the proper conditions have been satisfied.

The required conditions that need to be met in the PLC to enable the RMCS truck include the following:

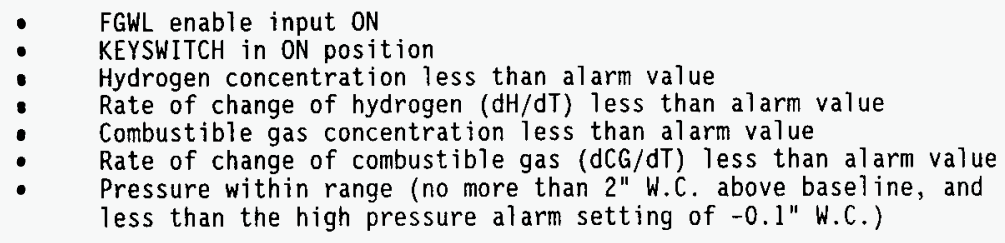

The required conditions that need to be met in the PLC to enable the portable exhauster include the following:

- FGWL enable input ON

- Pressure above low limit (pressure above -3" W.C.)

- Pressure signal OK (measured input greater than 2mA)

When the PLC senses that the POWER CONTACTOR relay is energized, the "POWER CONTACTOR" lamp is then illuminated under program control. 
WHC-SD-WM-CSDD-020, REV 0

\subsubsection{Shutdown}

The RMCS INTERLOCK relay (K10) can be de-energized by the conditions listed below:

- High hydrogen concentration

- High rate of change of hydrogen $(\mathrm{dH} / \mathrm{dT})$

- $\quad$ 2"W.C. above baseline pressure alarm

- High combustible gas concentration

- High rate of change of combustible gas (dCG/dT)

- High tank pressure

The PLC will light an indicator light, on the operator's console, identifying the condition causing the shutdown for the above conditions. This light is latched on, and will not extinguish until the KEYSWITCH is turned off, which will reset any latched alarms. Two additional events will cause the RMCS INTERLOCK relay to de-energize:

- Loss of A.C. Power

- KEYSWITCH in OFF position

The portable exhauster can be shut down by the following condition:

- Tank Low Pressure Alarm (-3" W.C. or below)

Again, the PLC will light an indicator light on the operator's console, identifying a PRESSURE alarm. This light is latched on, and will not extinguish until the KEYSWITCH is turned off, which will reset any latched alarms. The portable exhauster enable must be manually restarted from the EXH FAN START PERMISSIVE(S3) button. Four additional events will cause the portable exhauster to shut down:

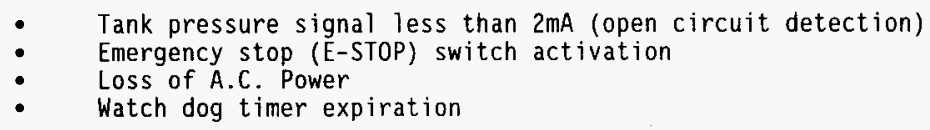

\subsubsection{High Hydrogen Concentration}

If a high hydrogen concentration (above $5000 \mathrm{ppm}$ ) is detected, the HYDROGEN lamp will be energized, the STROBE LIGHT relay coil (KI1) will energize, and the RMCS INTERLOCK relay coil (K10) will de-energize. This will cause the RMCS truck to shut down.

\subsubsection{High Rate of Change of Hydrogen Concentration (dH/dT)}

If a high rate of change of hydrogen concentration (above $100 \mathrm{ppm} / \mathrm{sec}$ for 10 seconds) is detected, the HYDROGEN lamp will be energized, the STROBE 
WHC-SD-WM-CSDD-020, REV 0

LIGHT relay coil (K11) will energize, and the RMCS INTERLOCK relay coil (K10) will de-energize. This will cause the RMCS truck to shut down.

\subsubsection{Cabinet Temperature Out of Range}

If the cabinet temperature is sensed to be outside of the high alarm setpoint ( 95 degrees $F$.) by the PLC, the CABINET TEMPERATURE OUT OF RANGE 1 amp will be energized. This lamp will al so be illuminated whenever the parallel HEATER BYPASS relay coil (K12) is energized, indicating the cabinet temperature is too low for PLC operation.

\subsubsection{2" W.C. Above Basel ine Pressure Alarm}

If the pressure is observed to be 2" W.C. above the baseline pressure, the PRESSURE lamp will be energized, the STROBE LIGHT relay coil (K11) will energize, and the RMCS INTERLOCK relay coil (K10) will de-energize. This will cause the RMCS truck to shut down.

NOTE: At power-up, a tank pressure reading is taken, and the high pressure alarm is set to 2 "W.C. above this background 7evel. As soon as the exhauster begins operating, a drop in pressure will occur, and 3 minutes later the high pressure alarm is set to $2^{\prime \prime}$ W.C. above this new pressure. Every 6 minutes during exhauster operation, the high pressure alarm is updated to 2" W.C. above the current tank pressure reading. This allows for normal tank pressure fluctuations.

\subsubsection{High Combustible Gas Concentration}

If the combustible gas concentration reaches the alarm limit (above 5000 ppm), the COMBUSTIBLE GASSES lamp will be energized, the STROBE LIGHT relay coi1 (K11) will energize, and the RMCS INTERLOCK relay coil (K10) will deenergize. This will cause the RMCS truck to shut down.

\subsubsection{High Rate of Change of Combustible Gas (dCG/dT)}

If a high rate of change of combustible gas concentration (above 100 $\mathrm{ppm} / \mathrm{sec}$ for 10 seconds) is detected, the COMBUSTIBLE GASSES 1 amp will be energized, the STROBE LIGHT relay Coil (K11) will energize, and the RMCS INTERLOCK relay coil (K10) will de-energize. This will cause the RMCS truck to shut down.

\subsubsection{Tank Pressure Alarm}

If the pressure is observed to be below -3" W.C., the PRESSURE lamp will be energized, the MOTOR STARTER relay coil (K6) will be de-energized, and the E-STOP relay coil (K5) will be toggled. This de-energizes the ENABLE POWER TO EXHAUSTER relay coil (K3). 
If the tank pressure is observed to be above -0.1 "W.C., the STROBE LIGHT relay coil (K11) will energize, and the RMCS INTERLOCK relay coil (K10) will de-energize. This will cause the RMCS truck to shut down.

\subsubsection{E-STOP}

The depression of the EMER STOP (S2) button directly de-energizes the POWER CONTACTOR and is sensed by the PLC by the EMER STOP pushbutton switch pole. The PLC then actuates the E-STOP relay coil (K5), redundantly deenergizing the POWER CONTACTOR relay coil (MS), which shuts down the exhauster.

\subsubsection{Watch Dog Timer}

A watch dog timer (WDT) must be periodically reset by the PLC any time the PLC is running. This is accomplished by energizing and de-energizing the WATCH DOG relay coil (K9) every second. The reset command will be evident to the operator by the flashing of the SYSTEM OK 1amp (DS2) at the operator's console. Toggling a N.0. relay contact closure (K9) resets the WDT. The WDT maintains a N.O. relay contact closure in the arming circuit. When the PLC begins operating on power-up, the WDT N.O. relay contact is initially closed. If the WDT fails to get reset by the PLC, the timer will expire and open the N.O. contact, de-energizing the POWER CONTACTOR (MS). This will be evident on the operator's panel by the cessation of the flashing of the SYSTEM OK lamp, a shutdown of power to the exhauster, and the loss of the POWER TO EXHAUSTER 1 amp (DS3). Additionally, if power fails, the N.O. contact closure will return to the N.0. state.

NOTE: If the FGWL ENABLE input (slot 4, input 7) is not sensed by the $P L C$, then the SYSTEM OK 7 amp will not flash and the watch dog timer will not be reset. The correct cables must be connected to the FGTEI carts at J5A (cart 2205) and J12A (cart 2206) to allow proper FGTEI operation.

Additionally, if the tank pressure signal input is less than 2mA, the SYSTEM OK lamp will not flash and the watch dog timer will not be reset. This indicates an open circuit from the tank pressure signal, or a failed pressure instrument.

\subsubsection{Loss of A.C. Power}

A loss of A.C. power will drop out all hard-wired relay coils, as well as de-energize the PLC. 'The start-up sequence must be performed to enable the RMCS truck and start the portable exhauster again. 
WHC-SD-WM-CSDD-020, REV 0

\subsubsection{Keyswitch}

The KEYSWITCH is used as a "Truck Enable" input, as well as a latched a larm reset. The portable exhauster does not require the keyswitch to be in the ON position to start, but the RMCS truck DOES require it's use. The KEYSWITCH must be in the ON position for alarms to be latched. To reset latched alarms, simply turn the KEYSWITCH to the OFF position and then back to the ON position.

\subsection{PLC SOFTWARE DESCRIPTION}

\subsection{GENERAL}

Ladder logic for the FGTEI has been developed utilizing FGTEI elementary diagrams and operational design information.

Programming the PLC is accomplished with a MS-DOS based 486 PC running Modsoft, a software package provided by Modicon, Inc. The ladder logic is downloaded to the PLC via an RS-232 link, referred to by Modicon as Modbus. This RS-232 connection will also provide the communication path when the FGTEI is connected to a laptop PC in the field (or during testing). Cart 2205 utilizes J1OA as the laptop interface connector, while cart 2206 uses J16A.

Included in the appendices of this document are:

- I/O channel list (Appendix A)

- Reference symbol table (Appendix B)

- PLC system configuration (Appendix C)

- Ladder logic network diagrams (Appendix D)

- Coil/register utilization tables (Appendix E)

- ADU206 control register reference (Appendix F)

\subsection{LADDER LOGIC NETWORK DESCRIPTIONS}

The following sections describe the individual networks that collectively make up the ladder logic of the FGTEI PLC system. Refer to Appendix $D$ for the appropriate ladder logic network diagram.

\subsubsection{Network 1 - Watch Dog / Powerup Delay Timers}

This network has two functions -- to control the pulse train to the watch dog timer and to provide a 10-second power-up delay timer for use with al arms. 
WHC-SD-WM-CSDD-020, REV 0

\subsubsection{Watch Dog Timer}

The watch dog timer (WDT) portion of this network uses an internal 0.1 second timer block, with a multiplier of 10 , to provide a pulse every 1.0 seconds.

A N.C. contact 204 (WDTCOUNT) controls the reset of the timer. Output coil WDTCOUNT energizes after I second, which resets the timer by opening the N.C. contact on the reset input. The timer output then de-energizes WDTCOUNT, which starts the timer again. This process is repeated continually while the PLC is in operation.

A SUB block uses the timer register 41200 (WDTTIMR) to provide a squarewave output to coil 12 (WDT0). Whenever WDTTIMR is less than 5, the WDTO coil is energized, and remains energized for 0.5 seconds.

NOTE: A N.O. contact 10007 (FGWLEI) is in series before WDTO. This requires FGWLEI to be energized for the WDTO coil to toggle as described above. This input is the FGWL ENABLE input (slat 4, input 7). See section 3.2.4.9.

An additional N.C. contact 402 is in series before WDTO. This contact is controlled by the status bit for the tank pressure signal input (see Network 4 - section 4.2.4). If the signal is measured to be <2mA, then coil 402 is energized, and the N.C. contact 402 opens up, disabling WOTO.

The WOTO coil is hardware-mapped to the WATCH DOG output relay coil (K9). The pulse output will cause flashing of the SYSTEM OK lamp at the operator's console. The WOT maintains a normally open (N.O.) relay contact closure in the arming circuit. If the WDT fails to get reset by the PLC, the timer will expire and open the N.O. contact closure, de-energizing the POWER CONTACTOR (MS). This will be evident on the operator's panel by the cessation of the flashing of the SYSTEM OK lamp, a shutdown of power to the exhauster, and the loss of the POWER TO EXHAUSTER 7amp.

\subsubsection{Powerup Delay Timer}

The purpose of this timer is to generate a contact closure for internal coil 205 (PWRUPTMR) 10 seconds after initial power up of the PLC. Using an internal 1.0 second timer block, with a multiplier of 10 , coil PWRUPTMR goes high 10 seconds after initial power up via internal coil 101 (POWERUP). Coil POWERUP is discussed in section 4.2.2.

This 10-second delay is used for two purposes. The first is to load the high pressure alarm limit to 2" W.C. above the background pressure. This is discussed in section 4.2.3. 
WHC-SD-WM-CSDD-020, REV 0

The second use for PWRUPTMR is to disable any alarm conditions for 10 seconds after power up, to ensure the instruments have stabilized. This is discussed in sections 4.2.10 and 4.2.11.

\subsubsection{Network 2 - Toggle HEATOfFo Relay (K4) / Set HIPRABVAL}

This network has two functions -- to toggle the Heater Bypass relay (K2) allowing the PLC to take control of the HVAC of the FGTEI cart and to set the pressure alarm limit for the exhauster during its operation.

\subsubsection{Toggle HEATOFFO Relay (K4)}

On power-up, internal coil 101 (POWERUP) is energized. Internal contacts from this coil are used throughout the FGTEI ladder logic, primarily to initialize values on power up of the PLC.

In this network, POWERUP, in series with a N.C. contact 10003 (HBYPASSI), controls the reset input for a 2 second timer. The 0.1 second timer block, with a multiplier of 20, holds the output of coil 7 (HEATOFFO) high for 2 seconds, then de-energizes it.

HEATOFFO is hardware-mapped to the HEATER OFF output reiay coil (K4), which will drop out relay coil K2 (and parallel relay coil K12), turning off the HEATER BYPASS.

A N.0. contact from K2 is hardware-mapped to coil 10003 (HBYPASSI). When HBYPASSI is closed, this also opens the N.C. contact from HBYPASSI and energizes HEATOFFO for two seconds. Therefore, when the PLC is first powered up, a 2-second energization of HEATOFFO occurs, as well as any time the EXH FAN START PERMISSIVE button is pressed (which causes HBYPASSI to energize K2).

\subsubsection{Set HIPRABVAL}

A 1.0 second timer block, with a multiplier of 180 , is used to generate an output 180 seconds ( 3 minutes) after the exhauster is started. A pulse is generated by a positive-transition from internal coil 206 (BKGNDTMR1). The pulse is used to perform an addition function when the exhauster is running to establish a new high pressure alarm limit (register 41013 - HIPRABVAL) to 2 "W.C. above the "running" baseline pressure level (register 30005 PRESSVAL).

An additional positive-transition contact from coil 207 (BKGNDTMR2) also causes HIPRABVAL to be updated with PRESSVAL plus 2" W.C. This occurs every 6 minutes while the exhauster is running, and is discussed in network 6 (section 4.2.6.2).

If the result of the SUB block is determined to be above 0 "W.C., then the following BLKM block moves ZERO (41003) into 41013 (HIPRABVAL). This 
WHC-SD-WM-CSDD-020, REV 0

ensures that the high pressure alarm limit never exceeds $O^{\text {" W,C. }}$

\subsubsection{Network 3 - A arm and Abort Initialization}

During power-up, the positive-edge recognition of POWERUP causes the N.O. contact 101 (POWERUP) to close. This enables the ADD blocks to perform the addition shown, but only one time due to the nature of a positive-edge triggered contact. The result of the ADD is transferred to the designated register used for setpoints for alarms, aborts, and temperature control.

The ADD blocks use constants added to other constants to accomplish the respective setpoint value transfers. Two MUL (multiply) blocks are used to create constants above the 1 imitation number of 999 for direct constant use. The first MUL block creates the number 2000 by placing $(500 \times 4)$ in the register pair at address 41300 . This places the number 2000 into register 41301 (TWOTHOUSAND). The remaining MUL block creates the number 3000 into register 41303 (THREETHOUSAND).

The first $A D D$ block adds 2000 to zero ( $\# 0000)$, placing the result into register 41006 (HH2ABVAL). This initializes the HIGH HYDROGEN ABORT setpoint value one time, at start-up.

The remaining $A D D$ blocks initialize the following:

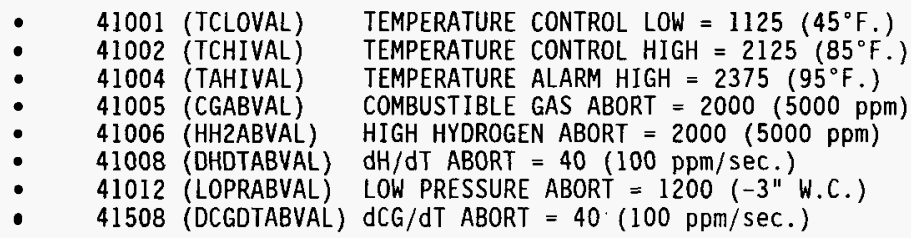

Al1 analog inputs are 4-20 mA. The ADU206 modules are configured to read 0 at $4 \mathrm{~mA}$, and 4000 at $20 \mathrm{~mA}$ (see section 4.2.4). The calibrations used for all inputs are as follows:

$$
\begin{array}{ll}
\text { Hydrogen: } & 0-4000=0 \text { to } 10,000 \mathrm{ppm}(2.5 \mathrm{ppm} / \text { count }) \\
\text { Combustible Gas: } & 0-4000=0 \text { to } 10,000 \mathrm{ppm}(2.5 \mathrm{ppm} / \text { count }) \\
\text { Pressure: } & 0-4000=0 \text { to }-10 \mathrm{~W} \text {.C. (.0025 "W.C./Count) } \\
\text { Temperatures: } & 0-4000=0 \text { to } 160 \text { degrees } \mathrm{F} .\left(.04^{\circ} \mathrm{F} / \text { count }\right)
\end{array}
$$

\subsubsection{Network 4 - ADU206 Initialization}

The ADU206 modules require an initialization register to be loaded prior to use. This network initializes the ADU206 4-channel analog input modules in slots 7 and 8 . One time only, upon power-up, a N.0. positive-edge triggered contact 101 (POWERUP) is closed. 
WHC-SD-WM-CSDD-020, REV 0

The single closure of POWERUP enables the ADD blocks to perform the addition shown. This transfers the result to the designated registers used to set the mode of operation for the ADU206 modules. Register 40001 (MOD1MODE) is used for the module in slot 7, and register 40002 (MOD2MODE) is used for the module in slot 8 .

ADD blocks are used to add constants to zero to accomplish this. For example, the first ADD block adds 112 (\#0112) to zero ( $\# 0000$ ), placing the result into register 40001 (MODIMODE). This initializes the ADU206 module to unipolar mode with offset and extended resolution (see Appendix F). In this mode, all 4-20 mA inputs are read as 0000 when $4 \mathrm{~mA}$ is input, and 4000 at 20 $\mathrm{mA}$.

This network also initializes the system constant ZERO to 0 . This is accomplished by adding $O$ to $O$ (using an ADD block) with the result placed into register 41003 (ZERO). This constant is used in networks 2, 13, and 15.

Register 41401 (HITANKPRESSVAL) is initialized to 40 (-0.1 "W.C.) in this network by using an ADD block to add 0 to 40 , storing the result into register 41401 .

Testing of the pressure signal input is also performed in this network with the use of a SENS (sense) block. Bit 13 in register 30001 (the ADU206 status register) will be set to a "1" if the input is sensed to be less than 2 mA. Should this happen, internal coil 402 will energize and the N.C. contact 402 used in Network 1 will open, causing the WDTO coil to stop pulsing (see section 4.2.1.1).

\subsubsection{Network 5 - Exhauster \& RMCS Truck Shutdown}

This network has three functions -- to control the power output to the portable exhauster (K6), to enable/disable the RMCS truck interlock (K10), and to control the ESTOP relay (K5).

\subsubsection{Exhauster (Motor Starter) Enable Output}

The MOTOR STARTER output relay (K6) is hardware-mapped to output coil 9 (MOTSTRTO). This coil is energized only when the tank pressure is above -3" W.C. (N.C. contact 300 - see section 4.2.11.1), the E-Stop switch is not pressed (N.O. but normally energized contact 10001), and the FGWL input is enabled (N.O. contact 10007), and the EXH FAN START PERMISSIVE switch is detected via the HEATER BYPASS (K2) N.0. contact, hardware-mapped to 10003 (HBYPASSI).

Once MOTSTRTO is energized, it is latched in place with a N.O. contact controlled by MOTSTRTO. The MOTSTRTO coil will de-energize only if the tank

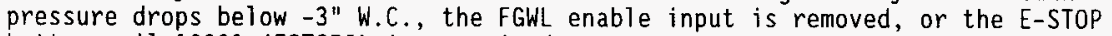
button coil 10001 (ESTOPI) is energized. 
WHC-SD-WM-CSDD-020, REV 0

\subsubsection{RMCS Interlock (K10)}

The RMCS INTERLOCK output relay (K10) is hardware-mapped to output coil 13 (RMCSO). This coil is energized only when no abort conditions exist (with the N.0. contact 100), the FGWL input is enabled (N.0. contact 10007), and the KEYSWITCH is enabled (with the N.O contact 10006).

The RMCSO coil will de-energize only if an abort condition occurs, the FGWL enable input is removed, or the KEYSWITCH is disabled. following:

The composite abort (coil 100) is made up with N.C. contacts from the

$\begin{array}{llll}- & 00001 & \text { (HIGHH20) } & \text { HIGH HYOROGEN CONCENTRATION \& dH/dT } \\ 0 & 00301 & \text { (DELTAPRESS) } & \text { DELTA PRESSURE ALARM } \\ 00004 & \text { (COMBGALO) } & \text { COMBUSTIBLE GAS ALARM \& dCG/dT and a } N .0 \\ \text { contact } & \text { from: } & \\ 10001 & \text { (ESTOPI) } & \text { E-STOP BUTTON INPUT }\end{array}$

Energizing any of the first three coils listed above (or de-energizing 10001 with the E-Stop button) will cause the composite coil 100 (COMPABORT) to de-energize. If RMCSO (which enables the RMCS truck interlock) is energized when this occurs, RMCSO will de-energize.

Additionally, the N.C. contacts from the first three coils above $(00001$, 00301 , and 00004) energize coil 208 (NOTSTROBE). This is the inverted strobe control output, and will be discussed in the following network (network 6).

\subsubsection{Network 6 - Strobe / Background Pressure}

This network has two distinct functions - to control the strobe light output, and to update the high-pressure abort level (2" W.C. above baseline pressure).

\subsubsection{Strobe Light Control}

Output coil 14 (STROBEO) is hardware-mapped to external relay STROBE LIGHT (KII). This output goes on when the coil to N.C. contact 208 (NOTSTROBE) is de-energized. This occurs under RMCS abort conditions (see section 4.2 .5 .2 ).

\subsubsection{Background Pressure Timer}

Coil 207 (BKGNDTMR2) is used to update the 2" W.C. above basel ine pressure abort (HIPRABVAL - as discussed in section 4.2.2.2) every six minutes while the exhauster is running. The N.O. contact 206 (BKGNDTMRI) is used as an indicator that the exhauster is running - it also serves as the start time after the initial 3-minute update. 
The N.C. contact 207 (in series with the N.0. contact 206) is used as a reset control for the 360 second timer block that controls coil 207. This timer block continualiy counts 360 seconds (six minutes), resets, and counts again while the exhauster is running. If the exhauster is stopped, then coil 206 will de-energize, causing the updates to discontinue (see section 4.2.2.2).

The SUB block is used to compare the real-time tank pressure (register 30001 - PRESSVAL) with the 2" W.C. above baseline pressure abort limit (register 41013 - HIPRABVAL). If the tank pressure is above the limit, then the alarm coil 301 (DELTAPRESS) is energized. However, the N.0. coil 206 (BKGNDTMR1) in series with coil 301 ensures that the alarm only occurs if the exhauster is running (coil 301 only aborts the portable exhauster, and since the 2" W.C. above baseline background pressure abort limit is updated only when the exhauster is running, HIPRABVAL will not have current information in it unless the exhauster is running).

The N.0. coil 10006 (KBYPASSI) is the keyswitch input. If it is energized (KEYSWITCH ON), then if coil 301 is energized, the coil is selflatching (with the use of the N.O. contact 301). The KEYSWITCH must be turned OFF to reset the alarm condition.

N.0. coil 401 (HITANKPRESS) will also energize coil 301 . This coil is controlled by the high tank pressure alarm of -0.1 "W.C. (see Network 9 section 4.2 .9 .4$)$.

\subsubsection{Network 7 - Low Temperature Control (HEAT)}

Output coil 11 (HEATONO) is hardware-mapped to external relay HEATER (K8). When the HEATER relay is energized, the heater is on.

Register 30002 (ICBTEVAL) is the Inside Cabinet Temperature. It is compared to the low temperature control setpoint (TCLOVAL) using a SUB block to perform a subtraction. If ICBTEVAL is less than TCLOVAL, then power is applied to the adjacent ADD block and cotl 200 (HEATCONTI) is energized. The function of the ADD block is to set the deadband for temperature control. The ADD block adds 125 ( 5 degrees $F$.) to the low temperature setpoint, TCLOVAL, and places it into register 41102 (HTCONDVAL), the heating control delta value.

When coil 200 (HEATCONT1) is energized, coil 201 (HEATCONT2) is also energized. This allows the N.0. contact from HEATCONT2 to pass power to the final SUB block, which performs the actual control to the heater. HTCONDVAL is subtracted from ICBTEVAL, and HEATONO is energized while ICBTEVAL is less than HTCONDVAL.

As HEATONO is energized, the N.O. contact will latch HEATCONT2 on until the temperature rises 5 degrees $F$. above the low temperature setpoint. 
WHC-SD-WM-CSDD-020, REV 0

\subsubsection{Network 8 - High Temperature Control (COOL)}

Output coil 10 (COOLONO) is hardware-mapped to external relay AIR CONDITIONER (K7). When relay AIR CONDITIONER is energized, the air conditioner is on.

Register 30002 (ICBTEVAL) is the Inside Cabinet Temperature. It is compared to the high temperature control setpoint (TCHIVAL) using a SUB block to perform a subtraction. If ICBTEVAL is greater than TCHIVAL, then power is applied to the adjacent SUB block and coil 202 (COOLCONT1) is energized. The function of this second SUB block is to set the deadband for temperature control. The SUB block subtracts 125 ( 5 degrees $F$.) from the high temperature setpoint, TCHIVAL, and places it into register 41103 (CTCONDVAL), the cooling control delta value.

When coil 202 (COOLCONT1) is energized, coil 203 (COOLCONT2) is also energized. This allows the N.O. contact from COOLCONT2 to pass power to the final SUB block, which performs the actual control to the air conditioner. CTCONDVAL is subtracted from ICBTEVAL, and COOLONO is energized while ICBTEVAL is greater than CTCONDVAL.

As COOLONO is energized, the N.O. contact will latch COOLCONT2 on until the temperature drops 5 degrees below the high temperature setpoint.

\subsubsection{Network 9 - Temp. Out of Range/Power to Exhauster/E-STOP/High Tank Pressure}

\subsubsection{Temperature Out of Range}

Energizing internal coil 2 (CABTEMPO) indicates that the cabinet temperature is out of range (high) for operating the PLC. The high alarm point ( 95 degrees $F$. ) is 10 degrees $F$. above the high temperature control setpoint ( 85 degrees $F$. .).

NOTE: External relay coil K12 (HEATER BYPASS - in parallel with K2) also will illuminate the CABINET TEMPERATURE OUT OF RANGE 7 amp, indicating that the temperature is too low to operate the PLC.

This network continually checks for an out of range condition, through the use of a SUB block. Register 41004 (TAHIVAL) is subtracted from register 30002 (ICBTEVAL), and coil 2 (CABTEMPO) is energized if ICBTEVAL is above TAHIVAL. lamp.

CABTEMPO is hardware-mapped to the CABINET TEMPERATURE OUT OF RANGE 
WHC-SD-WM-CSDD-020, REV 0

\subsubsection{Power To Exhauster Lamp}

Coil 15 (PWR2EXHSTRO) is hardware-mapped to the POWER TO EXHAUSTER lamp on the console (DS3). When the N.0. contact 10004 (MOTSTRTI) closes, coil 15 is energized, illuminating the POWER TO EXHAUSTER lamp. Coil 10004 is the input from the motor starter (MS) power contactor. When the power contactor is energized, a N.O. contact from the contactor closes, enabling input coil 10004.

\subsubsection{E-STOP}

Coil 8 is hardware-mapped to the E-STOP relay (K5). Under normal conditions, the N.C. contact 300 (PRESSABRT) and the N.0. contact 10001 (ESTOPI) keep coil 8 energized. Whenever the low pressure abort $(-3 " \mathrm{~W} . \mathrm{C}$.$) is$ detected, the N.C. contact 300 will open, causing coil 8 to de-energize, which causes K5 to de-energize. This will remove the power to the exhauster, requiring the EXH FAN START switch to be pressed to restart the exhauster.

Similarly, the N.O. contact 10001 is closed when the E-STOP button is not pressed. If an operator presses the E-STOP button, this will cause the N.O. contact 10001 to open, removing power to the exhauster by de-energizing K5.

\subsubsection{High Tank Pressure}

A high tank pressure alarm setting of -0.1 "W.C. will cause the RMCS truck to shut down with the use of coil 401 (HITANKPRESS). Network 6 uses a N.O. contact from coil 401 to generate a pressure alarm (see section 4.2.6.2). The pressure signal in register 30005 is compared with the high tank pressure alarm value (register 41401 - HITANKPRESSVAL). If the pressure is above this value, AND N.O. contact 206 is closed (indicating that the exhauster is running), then coil 401 is energized.

\subsubsection{Network 10 - Combustible Gas, Hydrogen Aborts}

This network has two distinct functions - to generate an abort if a high combustible gas concentration (rate or level) exists or a high-hydrogen limit (rate or level) is detected.

\subsubsection{Combustible Gas Abort}

Output coil 4 (COMBGALO) is energized whenever the combustible gas concentration exceeds a preset setpoint, or a $d C G / d T$ rate alarm exists. This is accomplished through the use of a SUB block, where register 41005 (CGABVAL), the combustible gas abort value, is subtracted from register 30003 (COMBGVAL), the combustible gas concentration. If COMBGVAL is greater than CGABVAL, COMBGALO is energized, causing an abort (see 4.2.5.2). However, N.0. contact 205 (PWRUPTMR) must be closed, indicating that at least 10 seconds 
WHC-SD-WM-CSDD-020, REV 0

\subsubsection{Power To Exhauster Lamp}

Coil 15 (PWR2EXHSTRO) is hardware-mapped to the POWER TO EXHAUSTER 1 amp on the console (DS3). When the N.0. contact 10004 (MOTSTRTI) closes, coil 15 is energized, illuminating the POWER TO EXHAUSTER lamp. Coil 10004 is the input from the motor starter (MS) power contactor. When the power contactor is energized, a N.O. contact from the contactor closes, enabling input coil 10004 .

\subsubsection{E-STOP}

Coil 8 is hardware-mapped to the E-STOP relay (K5). Under normal conditions, the N.C. contact 300 (PRESSABRT) and the N.0. contact 10001 (ESTOPI) keep coil 8 energized. Whenever the low pressure abort (-3" W.C.) is detected, the N.C. contact 300 will open, causing coil 8 to de-energize, which causes $\mathrm{K5}$ to de-energize. This will remove the power to the exhauster, requiring the EXH FAN START PERMISSIVE switch to be pressed to restart the exhauster.

Similarly, the N.O. contact 10001 is closed when the E-STOP button is not pressed. If an operator presses the E-STOP button, this will cause the N.O. contact 10001 to open, removing power to the exhauster by de-energizing K5.

\subsubsection{High Tank Pressure}

A high tank pressure alarm setting of -0.1 "W.C. will cause the RMCS truck to shut down with the use of coil 401 (HITANKPRESS). Network 6 uses a N.O. contact from coil 401 to generate a pressure alarm (see section 4.2.6.2). The pressure signal in register 30005 is compared with the high tank pressure alarm value (register 41401 - HITANKPRESSVAL). If the pressure is above this value, AND N.O. contact 206 is closed (indicating that the exhauster is running), then coil 401 is energized.

\subsubsection{Network 10 - Combustible Gas, Hydrogen Aborts}

This network has two distinct functions - to generate an abort if a high combustible gas concentration (rate or level) exists or a high-hydrogen limit (rate or level) is detected.

\subsubsection{Combustible Gas Abort}

Output coil 4 (COMBGALO) is energized whenever the combustible gas concentration exceeds a preset setpoint, or a $d C G / d T$ rate alarm exists. This is accomplished through the use of a SUB block, where register 41005 (CGABVAL), the combustible gas abort value, is subtracted from register 30003 (COMBGVAL), the combustible gas concentration. If COMBGVAL is greater than CGABVAL, COMBGALO is energized, causing an abort (see 4.2.5.2). However, N.O. 
WHC-SD-WM-CSDD-020, REV 0

pressure signal. If PRESSVAL is less than LOPRABVAL, Coil 300 (PRESSABRT) is energized, causing an abort (see 4.2.5.1). However, N.0. contact 205 (PWRUPTMR) must be closed, indicating that at least 10 seconds have elapsed since power up of the PLC (see section 4.2.1.2).

A N.O. contact from PRESSABRT is used in series with a N.O. contact from coil 10006 (KBYPASSI) to latch the alarm. Whenever the KEYSWITCH is turned OFF, de-energizing KBYPASSI, the alarm is reset.

\subsubsection{Pressure Alarm Lamp}

Output coil 3 (PRESSALO) energizes whenever the 2" W.C. above baseline condition occurs (N.0. contact 301 - see 4.2.6.2), the high tank pressure alarm value is exceeded (coil 401 controlling coil 301 - see 4.2.9.4), or the low pressure abort exists (N.0. contact 300 - see 4.2.11.1). PRESSALO is hardware-mapped to the PRESSURE lamp.

\subsubsection{Network $12-\mathrm{dH} / \mathrm{dT}$ Data Capture}

The purpose of the $\mathrm{dH} / \mathrm{dT}$ data capture network is to provide two registers containing real-time hydrogen concentration data, separated by a preset time delay. This allows the hydrogen rate of change to be determined in network 13 (see 4.2.13).

A 0.01 second timer block, with a multiplier of 200 , counts to 200 in register 41201 (DHDTTIMR) and outputs a pulse to coil 102 (DHDTTIMER), which resets itself and counts to 200 again, providing a pulse every 2 seconds.

The first SUB block is used to subtract 100 from DHDTTIMR. If DHDTTIMR is greater than 100, coil 103 (DHDTCAP), the dH/dT capture control coil, is energized. This provides a square wave with a period of 2 seconds. Any rising edge is always 1 second from the next falling edge, and vice-versa. Therefore, a positive edge triggering one data capture register and a negative edge triggering another data capture register results in the two registers containing data points 1 second apart.

Precision data capture is accomplished by using registers 41009 (DHDTVAL1) and 41010 (DHDTVAL2). Zero is subtracted from register 30004 (H2VAL) and placed in these registers, controlled by a positive edge of DHDTCAP (into DHDTVAL1) and a negative edge of DHDTCAP (into DHDTVAL2), as explained above.

These two registers, DHDTVALI and DHDTVAL2, are continually updated while the PLC is operating. Network 13 (see 4.2.13) uses these registers to determine the $\mathrm{dH} / \mathrm{dT}$ (rate of change of hydrogen concentration) and to test for an abort condition. 
WHC-SD-WM-CSDD-020, REV 0

\subsubsection{Network $13-\mathrm{dH} / \mathrm{dT} \mathrm{Al}$ arm and Abort}

A rising edge of coil 103 (DHDTCAP) is used to control a SUB block that subtracts register 41010 (DHDTVAL2) from register 41009 (DHDTVAL1). The result is placed into register 41007 (DHDTRAW), the $\mathrm{dH} / \mathrm{dT}$ rate raw value. This positive-edge triggering is required to ensure that every time the subtract occurs, DHDTVALI is captured I second after DHDTVAL2.

If DHDTVALI is greater than DHDTVAL2 (implying the rate of change is positive), then the value in register 41007 (DHDTRAW) is placed into register 41011 (DHDTRVAL) via a BLKM block.

When DHDTVAL1 is less than or equal to DHDTVAL2 (implying the $\mathrm{dH} / \mathrm{dT}$ rate is non-positive), then register 41003 (ZERO) is placed into register DHDTRVAL with another BLKM block.

Register 41008 (DHDTABVAL), the $\mathrm{dH} / \mathrm{dT}$ abort value, is subtracted from DHDTRVAL in the following SUB block. If DHDTRVAL is greater than DHDTABVAL, then coil 104 (DHDTALARM) is energized, indicating the rate of change is greater than the abort setpoint.

The 0.1 second timer block, with a multiplier of 100 , is used to filter the $\mathrm{dH} / \mathrm{dT}$ value. DHDTALARM must be energized for a minimum of 10 seconds to cause a dH/dT abort condition. When DHDTALARM is high, the N.0. contact from DHDTALARM closes and the timer starts to count. If DHDTALARM remains high for 10 seconds, the timer output energizes coil 105 (DHDTABORT), the abort coil for the $\mathrm{dH} / \mathrm{dT}$ hydrogen rate. If DHDTABORT is energized an abort occurs (see 4.2.5.2). If at any time DHDTALARM is de-energized, the timer resets and DHDTABORT is also de-energized.

\subsubsection{Network 14 - dCG/dT Data Capture}

The purpose of the $\mathrm{dCG} / \mathrm{dT}$ data capture network is to provide two registers containing real-time combustible gas (CG) concentration data, separated by a preset time delay. This allows the CG rate of change to be determined in network 15 (see 4.2.15).

A 0.01 second timer block, with a multiplier of 200 , counts to 200 in register 41501 (DCGDTTIMR) and outputs a pulse to coil 502 (DCGDTTIMER), which resets itself and counts to 200 again, providing a pulse every 2 seconds.

The first SUB block is used to subtract 100 from DCGDTTIMR. If DCGDTTIMR is greater than 100 , coil 503 (DCGDTCAP), the dCG/dT capture control coil, is energized. This provides a square wave with a period of 2 seconds. Any rising edge is always 1 second from the next falling edge, and vice-versa. Therefore, a positive edge triggering one data capture register and a negative edge triggering another data capture register results in the two registers containing data points 1 second apart. 
WHC-SD-WM-CSDD-020, REV 0

Precision data capture is accomplished by using registers 41509 (DCGDTVAL1) and 41510 (DCGDTVAL2). Zero is subtracted from register 30003 (COMBGVAL) and placed in these registers, controlled by a positive edge of DCGDTCAP (into DCGDTVAL1) and a negative edge of DCGDTCAP (into DCGDTVAL2), as explained above.

These two registers, DCGDTVAL1 and DCGDTVAL2, are continually updated while the PLC is operating. Network 15 (see 4.2.15) uses these registers to determine the dCG/dT (rate of change of combustible gas concentration) and to test for an abort condition.

\subsubsection{Network $15-\mathrm{dCG} / \mathrm{dT}$ Alarm and Abort}

A rising edge of coil 503 (DCGDTCAP) is used to control a SUB block that subtracts register 41510 (DCGDTVAL2) from register 41509 (DCGDTVAL1). The result is placed into register 41507 (DCGDTRAW), the dCG/dT rate raw value. This positive-edge triggering is required to ensure that every time the subtract occurs, DCGDTVAL1 is captured 1 second after DCGDTVAL2.

If DCGDTVALl is greater than DCGDTVAL2 (implying the rate of change is positive), then the value in register 41507 (DCGDTRAW) is placed into register 41511 (DCGDTRVAL) via a BLKM block.

When DCGDTVALl is less than or equal to DCGDTVAL2 (implying the dCG/dT rate is non-positive), then register 41003 (ZERO) is placed into register DCGDTRVAL with another BLKM block.

Register 41508 (DCGDTABVAL), the $d C G / d T$ abort value, is subtracted from DCGDTRVAL in the following SUB block. If DCGDTRVAL is greater than DCGDTABVAL, then Coil 504 (DCGDTALARM) is energized, indicating the rate of change is greater than the abort setpoint.

The 0.1 second timer block, with a multiplier of 100 , is used to filter the dCG/dT value. DCGDTALARM must be energized for a minimum of 10 seconds to cause a dCG/dT abort condition. When DCGDTALARM is high, the N.O. contact from DCGDTALARM closes and the timer starts to count. If DCGDTALARM remains high for 10 seconds, the timer output energizes coil 505 (DCGDTABORT), the abort coil for the dCG/dT combustible gas rate. If DCGDTABORT is energized an abort occurs (see 4.2.5.2). If at any time DCGDTALARM is de-energized, the timer resets and DCGDTABORT is also de-energized. 
WHC-SD-WM-CSDD-020, REV O

\section{APPENDIX A}

I/0 Channe1 List

Page 22 
WHC-SD-WM-CSDD-020, REV 0

\begin{tabular}{|c|c|c|c|c|c|c|}
\hline DROP & RACK & SLOT & CHANNEL & REGISTER & TAGNAME & DESCRIPTION \\
\hline 1 & 1 & 1 & N/A & $N / A$ & & \multirow[b]{2}{*}{ PC-A984-145 } \\
\hline 1 & $i$ & 2 & $\mathrm{~N} / \mathrm{A}$ & $\mathrm{N} / \mathrm{A}$ & & \\
\hline 1 & 1 & 3 & $\mathrm{~N} / \mathrm{A}$ & $N / A$ & & AS-P120-000 \\
\hline 1 & 1 & 4 & $N / A$ & $100 \times x$ & & AS-BDEP-218 \\
\hline 1 & 1 & 4 & 1 & 10001 & ESTOPI & Exhauster ESTOP In \\
\hline 1 & 1 & 4 & 2 & 10002 & EXHSTRI & Exh. (CT) Running In \\
\hline 1 & 1 & 4 & 3 & 10003 & HBYPASSI & Heater Bypass In \\
\hline 1 & 1 & 4 & 4 & 10004 & MOTSTRTI & Motor Starter In \\
\hline 1 & 1 & 4 & 5 & 10005 & ESTOPFI & ESTOP Feedback In \\
\hline 1 & 1 & 4 & 6 & 10006 & KBYPASSI & Keyswitch Bypass In \\
\hline 1 & 1 & 4 & 7 & 10007 & FGWLEI & FGWL Enable In \\
\hline 1 & 1 & 4 & 8 & 10008 & EXFANRUNI & Exh. Fan Running In \\
\hline 1 & 1 & 4 & 9 & 10009 & & Spare \\
\hline 1 & 1 & 4 & 10 & 10010 & & Spare \\
\hline 1 & 1 & 4 & 11 & 10011 & & Spare \\
\hline 1 & 1 & 4 & 12 & 10012 & & Spare \\
\hline 1 & 1 & 4 & 13 & 10013 & & Spare \\
\hline 1 & 1 & 4 & 14 & 10014 & & Spare \\
\hline 1 & 1 & 4 & 15 & 10015 & & Spare \\
\hline 1 & 1 & 4 & 16 & 10016 & & Spare \\
\hline 1 & 1 & 5 & $N / A$ & $000 \times x$ & & AS-BDAP-218 \\
\hline 1 & 1 & 5 & 1 & 00001 & HIGHH2O & High Hydrogen Out \\
\hline 1 & 1 & 5 & 2 & 00002 & CABTEMPO & Cab. Temp. ooR out \\
\hline 1 & 1 & 5 & 3 & 00003 & PRESSALO & Pressure Alarm Out \\
\hline 1 & 1 & 5 & 4 & 00004 & COMBGALO & Comb. Gas Alarm Out \\
\hline 1 & 1 & 5 & 5 & 00005 & AUX10 & Aux 1 out \\
\hline 1 & 1 & 5 & 6 & 00006 & AUX20 & Aux 2 out \\
\hline 1 & 1 & 5 & 7 & 00007 & HEATOFFO & Heater off Out \\
\hline
\end{tabular}


WHC-SD-WM-CSDD-020, REV 0

\begin{tabular}{||c|c|c|c|c|l|l||}
\hline 1 & 1 & 5 & 8 & 00008 & ESTOPO & EXhauster ESTOP Out \\
\hline 1 & 1 & 5 & 9 & 00009 & MOTSTRTO & Motor Starter Out \\
\hline \hline DROP & RACK & SLOT & CHANNEL & REGISTER & TAGNAME & DESCRIPTION \\
\hline 1 & 1 & 5 & 10 & 00010 & COOLONO & Air Cond. On Out \\
\hline 1 & 1 & 5 & 11 & 00011 & HEATONO & Heater On Out \\
\hline 1 & 1 & 5 & 12 & 00012 & WDTO & Watch Dog Timer Out \\
\hline 1 & 1 & 5 & 13 & 00013 & RMCSO & RMCS Interlock Out \\
\hline 1 & 1 & 5 & 14 & 00014 & STROBE0 & Strobe Light Out \\
\hline 1 & 1 & 5 & 15 & 00015 & PWR2EXHSTRO & Pwr. to EX. Lamp Out \\
\hline 1 & 1 & 5 & 16 & 00016 & & Spare \\
\hline \hline 1 & 2 & 1 & N/A & $000 X X$ & & AS-BDAP-218 \\
\hline 1 & 2 & 1 & 1 & 00017 & & Spare \\
\hline 1 & 2 & 1 & 2 & 00018 & & Spare \\
\hline 1 & 2 & 1 & 3 & 00019 & & Spare \\
\hline 1 & 2 & 1 & 4 & 00020 & & Spare \\
\hline 1 & 2 & 1 & 5 & 00021 & & Spare \\
\hline 1 & 2 & 1 & 6 & 00022 & & Spare \\
\hline 1 & 2 & 1 & 7 & 00023 & & Spare \\
\hline 1 & 2 & 1 & 8 & 00024 & & Spare \\
\hline 1 & 2 & 1 & 9 & 00025 & & Spare \\
\hline 1 & 2 & 1 & 10 & 00026 & & Spare \\
\hline 1 & 2 & 1 & 11 & 00027 & & Spare \\
\hline 1 & 2 & 1 & 12 & 00028 & & Spare \\
\hline 1 & 2 & 1 & 13 & 00029 & & Spare \\
\hline 1 & 2 & 1 & 14 & 00030 & & Spare \\
\hline 1 & 2 & 1 & 15 & 00031 & & Spare \\
\hline 1 & 2 & 1 & 16 & 00032 & & Spare \\
\hline 1 & 2 & 2 & N/A & $3 \times / 4 X$ & & AS-BADU-206 \\
\hline 1 & 2 & 2 & N/A & 30001 & MOD1STAT & ADU206 Op. Status \\
\hline
\end{tabular}


WHC-SD-WM-CSDD-020, REV 0

\begin{tabular}{|c|c|c|c|c|l|l||}
\hline 1 & 2 & 2 & 1 & 30002 & ICBTEVAL & Inside Cab. Temp. \\
\hline 1 & 2 & 2 & 2 & 30003 & COMBGVAL & Combust. Gasses \\
\hline 1 & 2 & 2 & 3 & 30004 & H2VAL & Whittaker H2 Signa] \\
\hline 1 & 2 & 2 & 4 & 30005 & PRESSVAL & Pressure \\
\hline \hline DROP & RACK & SLOT & CHANNEL & REGISTER & TAGNAME & DESCRIPTION \\
\hline 1 & 2 & 2 & N/A & 40001 & MODIMODE & ADU206 Mode/Range \\
\hline 1 & 2 & 3 & N/A & $3 \times / 4 X$ & & AS-BADU-206 \\
\hline \hline 1 & 2 & 3 & N/A & 30006 & MOD2STAT & ADU206 Op. Status \\
\hline 1 & 2 & 3 & 1 & 30007 & OCBTEVAL & Outside Cab. Temp. \\
\hline 1 & 2 & 3 & 2 & 30008 & & Spare \\
\hline 1 & 2 & 3 & 3 & 30009 & & Spare \\
\hline 1 & 2 & 3 & 4 & 30010 & & Spare \\
\hline 1 & 2 & 3 & N/A & 40002 & MOD2MODE & ADU206 Mode/Range \\
\hline 1 & 2 & 4 & N/A & N/A & & AS-P120-000 \\
\hline
\end{tabular}


WHC-SD-WM-CSDD-020, REV 0

APPENDIX B

Reference Symbol Table

Page 26 
Discrete Output Coils

\begin{tabular}{|c|c|c|c|}
\hline $\begin{array}{l}00001 \\
00002 \\
00003 \\
00004 \\
00005 \\
00006 \\
00007 \\
00008 \\
00009 \\
00010 \\
00011 \\
00012 \\
00013 \\
00014 \\
00015 \\
00016 \\
00017 \\
00018 \\
00019 \\
00020 \\
00021 \\
00022 \\
00023 \\
00024 \\
00025 \\
00026 \\
00027 \\
00028 \\
00029 \\
00030 \\
00031 \\
00032\end{array}$ & $\begin{array}{l}\text { HIGHH20 } \\
\text { CABTEMPO } \\
\text { PRESSALO } \\
\text { COMBGALO } \\
\text { AUX10 } \\
\text { AUX20 } \\
\text { HEATOFFO } \\
\text { ESTOPO } \\
\text { MOTSTRTO } \\
\text { COOLONO } \\
\text { HEATONO } \\
\text { WDTO } \\
\text { RMCSO } \\
\text { STROBEO } \\
\text { PWR2EXHSTRO }\end{array}$ & $\begin{array}{l}1.1 .5 \cdot 1 \\
1.1 .5 .2 \\
1.1 .5 .3 \\
1.1 .5 .4 \\
1.1 .5 .6 \\
1.1 .5 .7 \\
1.1 .5 .8 \\
1.1 .5 .9 \\
1.1 .5 .10 \\
1.1 .5 .11 \\
1.1 .5 .12 \\
1.1 .5 .13 \\
1.1 .5 .15 \\
1.1 .5 .16 \\
1.2 .1 .1 \\
1.2 .1 .2 \\
1.2 .1 .3 \\
1.2 .1 .4 \\
1.2 .1 .5 \\
1.2 .1 .6 \\
1.2 .1 .7 \\
1.2 .1 .8 \\
1.2 .1 .9 \\
1.2 .1 .10 \\
1.2 .1 .11 \\
1.2 .1 .12 \\
1.2 .1 .13 \\
1.2 .1 .14 \\
1.2 .1 .15 \\
1.2 .1 .16\end{array}$ & $\begin{array}{l}\text { High Hydrogen Out } \\
\text { Cabinet Temp. Out of Range Out } \\
\text { Pressure Alarm Out } \\
\text { Combustible Gas Alarm Out } \\
\text { Aux } 1 \text { Out } \\
\text { Aux } 2 \text { Out } \\
\text { Heater Off Out } \\
\text { Exhauster ESTOP Out } \\
\text { Motor Starter Out } \\
\text { Air Conditioning On Out } \\
\text { Heater On Out } \\
\text { Watch Dog Timer Out } \\
\text { RMCS Interlock Out } \\
\text { Strobe Light Out } \\
\text { Power To Exhauster Lamp Out } \\
\text { Spare } \\
\text { Spare } \\
\text { Spare } \\
\text { Spare } \\
\text { Spare } \\
\text { Spare } \\
\text { Spare } \\
\text { Spare } \\
\text { Spare } \\
\text { Spare } \\
\text { Spare } \\
\text { Spare } \\
\text { Spare } \\
\text { Spare } \\
\text { Spare } \\
\text { Spare } \\
\text { Spare }\end{array}$ \\
\hline
\end{tabular}


Discrete Internal Coits

\begin{tabular}{|c|c|}
\hline $\begin{array}{l}00100 \\
00101 \\
00102 \\
00103 \\
00104 \\
00105 \\
00200 \\
00201 \\
00202 \\
00203 \\
00204 \\
00205 \\
00206 \\
00207 \\
00208 \\
00209 \\
00300 \\
00401 \\
00402 \\
00301 \\
00502 \\
00503 \\
00504 \\
00505\end{array}$ & $\begin{array}{l}\text { COMPABORT } \\
\text { POWERUP } \\
\text { DHDTTIMER } \\
\text { DHDTCAP } \\
\text { DHDTALARM } \\
\text { DHDTABORT } \\
\text { HEATCONT1 } \\
\text { HEATCONT2 } \\
\text { COOLCONT1 } \\
\text { COOLCONT2 } \\
\text { WDTCOUNT } \\
\text { PWRUPTMR } \\
\text { BCKGNDTMR1 } \\
\text { BCKGNDTMR2 } \\
\text { NOTSTROBE } \\
\text { NOTRMCSO } \\
\text { PRESSABRT } \\
\text { HITANKPRESS } \\
\text { PRESSUREBAD } \\
\text { DELTAPRESS } \\
\text { DCGDTTIMER } \\
\text { DCGDTCAP } \\
\text { DCGDTALARM } \\
\text { DCGDTABORT }\end{array}$ \\
\hline
\end{tabular}

Discrete Input Registers

\begin{tabular}{|c|c|c|}
\hline $\begin{array}{ll}10001 & \text { ESTOPI } \\
10002 & \text { EXHSTRI } \\
10003 & \text { HBYPASSI } \\
10004 & \text { MOTSTRTI } \\
10005 & \text { ESTOPFI } \\
10006 & \text { KBYPASSI } \\
10007 & \text { FGWLEI } \\
10008 & \text { EXFANRUNI } \\
10009 & \\
10010 \\
10011 \\
10012 \\
10013 \\
10014 \\
10015 \\
10016\end{array}$ & $\begin{array}{l}1.1 .4 .1 \\
1.1 .4 .2 \\
1.1 .4 .3 \\
1.1 .4 .4 \\
1.1 .4 .5 \\
1.1 .4 .6 \\
1.1 .4 .7 \\
1.1 .4 .8 \\
1.1 .4 .9 \\
1.1 .4 .10 \\
1.1 .4 .11 \\
1.1 .4 .12 \\
1.1 .4 .13 \\
1.1 .4 .14 \\
1.1 .4 .15 \\
1.1 .4 .16\end{array}$ & $\begin{array}{l}\text { Exhauster ESTOP In } \\
\text { Exhauster Running In } \\
\text { Heater Bypass In } \\
\text { Motor Starter In } \\
\text { ESTOP Feedback In } \\
\text { Keyswitch Bypass In } \\
\text { FGWL Enable In } \\
\text { Exhauster Fan Running In } \\
\text { Spare } \\
\text { Spare } \\
\text { Spare } \\
\text { Spare } \\
\text { Spare } \\
\text { Spare } \\
\text { Spare } \\
\text { Spare }\end{array}$ \\
\hline
\end{tabular}

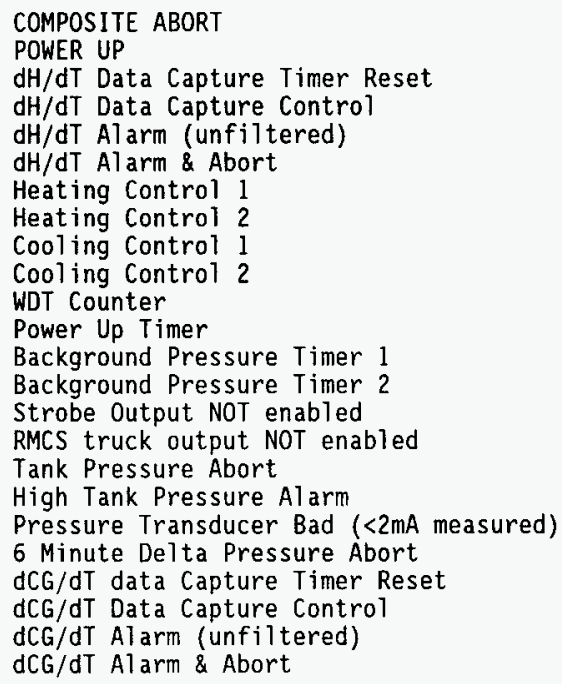

d


WHC-SD-WM-CSDD-020, REV 0

Analog Input Registers

30001 MODISTAT

30002 ICBTEVAL

30003 COMBGVAL

30004 H2VAL

30005 PRESSVAL

30006 MOD2STAT

30007 OCBTEVAL

30008

30009

30010

Output Registers

40001 MODIMODE

40002 MOD2MODE
Module 1 (ADU206) Operation Status Register Inside Cabinet Temperature

Combustible Gasses

Whittaker $\mathrm{H} 2$ Signal

Pressure

Module 2 (ADU206) Operation Status Register

1.2.3.1 Outside Cabinet Temperature

1.2.3.2 Spare

1.2.3.3 Spare

1.2.3.4 Spare

Module 1 (ADU206) Mode/Range Register

Module 2 (ADU206) Mode/Range Register 
WHC-SD-WM-CSDD-020, REV 0

Holding Registers

$\begin{array}{lll}41001 & \text { TCLOVAL } & \text { Temperature Control Low Value } \\ 41002 & \text { TCHIVAL } & \text { Temperature Control High Value } \\ 41003 & \text { ZERO } & \text { System Zero } \\ 41004 & \text { TAHIVAL } & \text { Temperature Alarm High Value } \\ 41005 & \text { CGABVAL } & \text { Combustible Gas Abort Value } \\ 41006 & \text { HH2ABVAL } & \text { High Hydrogen Abort Value } \\ 41007 & \text { DHDTRAW } & \text { dH/dT Raw Unsigned Value } \\ 41008 & \text { DHDTABVAL } & \text { dH/dT Abort Value } \\ 41009 & \text { DHDTVALl } & \text { dH/dT Value } 1 \\ 41010 \text { DHDTVAL2 } & \text { dH/dT Value } \\ 41011 & \text { DHDTRVAL } & \text { dH/dT Rate Value } \\ 41012 & \text { LOPRABVAL } & \text { Low Pressure Abort Value } \\ 41013 & \text { HIPRABVAL } & \text { High Pressure Abort Value } \\ 41101 & \text { SCRATCH } & \text { Heating Control Delta Value } \\ 41102 & \text { HTCONDVAL } & \text { Cooling Control Delta Value } \\ 41103 \text { CTCONDVAL } & \text { WDT Timer Register } \\ 41200 & \text { WDTTIMR } & \text { dH/dT Timer Register } \\ 41201 & \text { DHDTTIMR } & \text { dH/dT Filter Timer Register } \\ 41202 & \text { DHDTFTIMR } & \text { Hydrogen Startup Delay Timer Register } \\ 41203 & \text { H2DLYTIMR } & \text { Power Up Delay Timer Register } \\ 41204 & \text { PWRUPTIMR } & \text { Heat Off Pulse Timer Register } \\ 41205 & \text { HTOFFTMR } & \text { Exhauster Running Delay Timer Register } \\ 41207 & \text { EXHSTRTMR } & \text { Background Pressure Update Timer } \\ 41208 & \text { BCKGNDTMR } & \text { System Constant (2000) } \\ 41301 & \text { TWOTHOUSAND } & \text { System Constant (3000) } \\ 41303 \text { THREETHOUSAND } & \text { Hi Tank Pressure Alarm point (-0.1"W.C.) } \\ 41401 & \text { HITANKPRESSVAL } & \text { dCG/dT Timer Register } \\ 41501 & \text { DCGDTTIMR } & \text { dCG/dT Filter Timer Register } \\ 41502 & \text { DCGTFTIMR } & \text { dCG/dT Raw Unsigned Value } \\ 41507 & \text { DCGDTRAW } & \text { dCG/dT Abort Value } \\ 41508 & \text { DCGDTABVAL } & \text { dCG/dT Value l } \\ 41509 & \text { DCGDTVAL1 } & \text { dCG/dT Value 2 } \\ 41510 & \text { DCGDTVAL2 } & \text { dCG/dT Rate Value } \\ 41511 & \text { DCGDTRVAL } & \end{array}$


WHC-SD-WM-CSDD-020, REV 0

\section{APPENDIX C}

PLC System Configuration

Page 31 
FGTEI Ladder Logic - July 2, 1996

\section{Configuration}

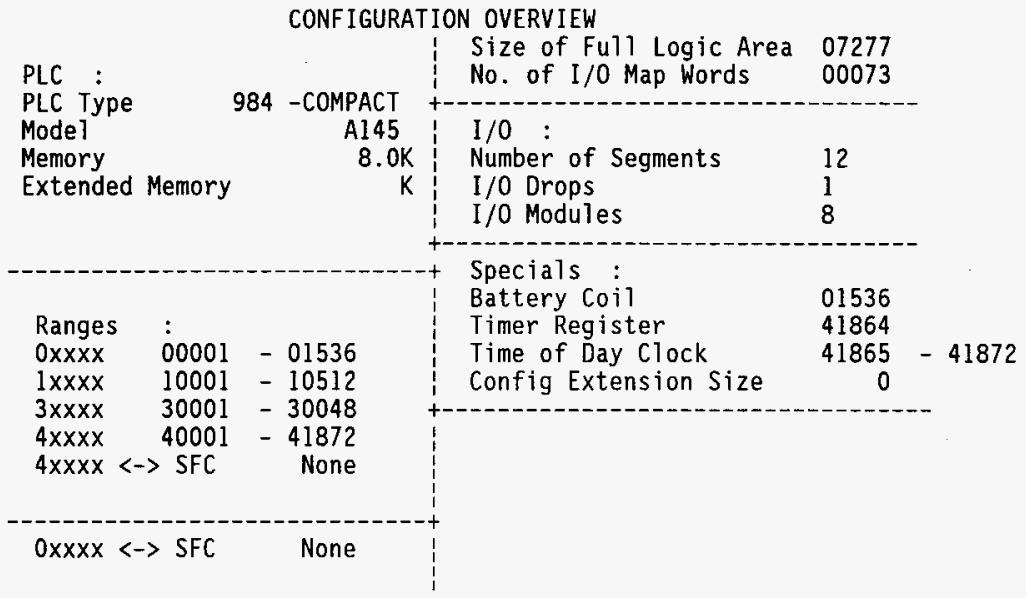

CONFIGURATION EXTENSION BLOCKS

No Configuration Extensions found

PORTS

Number Mode Data Bits Parity Stop Bits Baud Keyboard Address Delay MODBUS

01

02

$$
\text { RTU }
$$

RTU

$\begin{array}{ll}8 & \text { EVEN } \\ 8 & \text { EVEN }\end{array}$

9600

9600

$\begin{array}{ll}1 & 10 \mathrm{~ms} \\ 1 & 10 \mathrm{~ms}\end{array}$

I/O MAP

984-120/130/145 CONTROLLERS

$\begin{array}{llll}\text { PLC } & \text { COMPACT A145 } & \text { Rack } & : \\ \text { Number Inputs }: & 176 & \text { Number Outputs: } & 64\end{array}$




\begin{tabular}{|c|c|c|c|c|c|}
\hline jot & Type & Input & Output & type & Description \\
\hline $\begin{array}{l}101 \\
102 \\
103 \\
104 \\
105\end{array}$ & $\begin{array}{l}984 \\
984 \\
\text { P120 } \\
\text { DEP218 } \\
\text { DAP218 }\end{array}$ & $10001-10016$ & $00001-00016$ & & $\begin{array}{l}\text { PLC-COMPACT } \\
\text { PLC-COMPACT } \\
\text { POWER SUPPLY } \\
16-1 \quad 115 V A C \\
16-0115 V A C\end{array}$ \\
\hline
\end{tabular}

\begin{tabular}{|c|c|c|c|c|c|c|}
\hline PLC & : & COMPACT & A145 & Rack & : & 2 \\
\hline Slot & $\begin{array}{l}\text { Module } \\
\text { Type }\end{array}$ & $\begin{array}{l}\text { Reference } \\
\text { Input }\end{array}$ & $\begin{array}{r}\text { Number } \\
\text { Out }\end{array}$ & & $\begin{array}{l}\text { Data } \\
\text { type }\end{array}$ & $\begin{array}{l}\text { Module } \\
\text { Description }\end{array}$ \\
\hline $\begin{array}{l}201 \\
202 \\
203 \\
204 \\
205\end{array}$ & $\begin{array}{l}\text { DAP218 } \\
\text { ADU206 } \\
\text { ADU206 } \\
\text { P120 } \\
* * \text { AVA }\end{array}$ & $\begin{array}{rr}30001 & -30005 \\
30006 & -30010 \\
& \\
\text { ILABLE SLOT }\end{array}$ & $\begin{array}{l}0001 \\
4000 \\
4000\end{array}$ & $\begin{array}{ll}7 & -00032 \\
1 & -40001 \\
2 & -40002\end{array}$ & $\begin{array}{l}\text { BIN } \\
\text { BIN }\end{array}$ & $\begin{array}{l}15-0 \text { 115VAC } \\
4 \text { CHN A/D } \\
4 \text { CHN A/D } \\
\text { POWER SUPPLY }\end{array}$ \\
\hline
\end{tabular}


WHC-SD-WM-CSDD-020, REV 0

APPENDIX D

Ladder logic Network Diagrams

Page 34 
FGTEI Ladder Logic - July 2, 1996

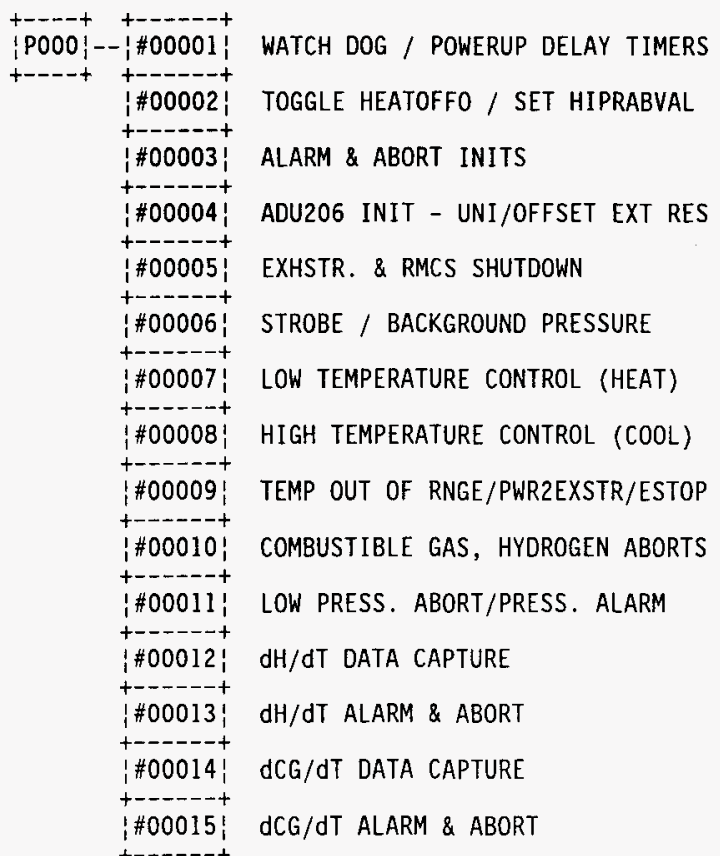


WHC-SD-WM-CSOD-020, REV 0

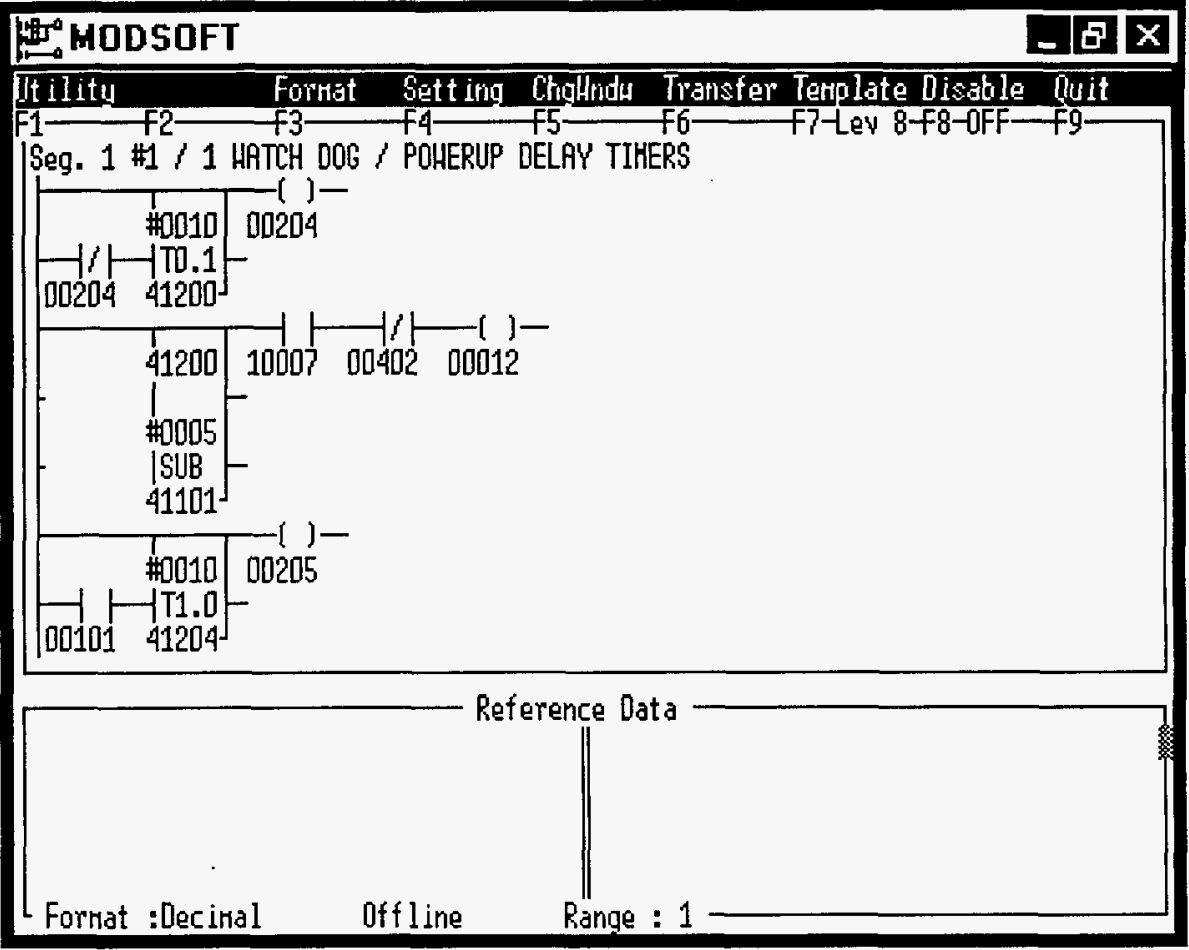


WHC-SD-WM-CSDD-020, REV 0

\section{MODSOFI}

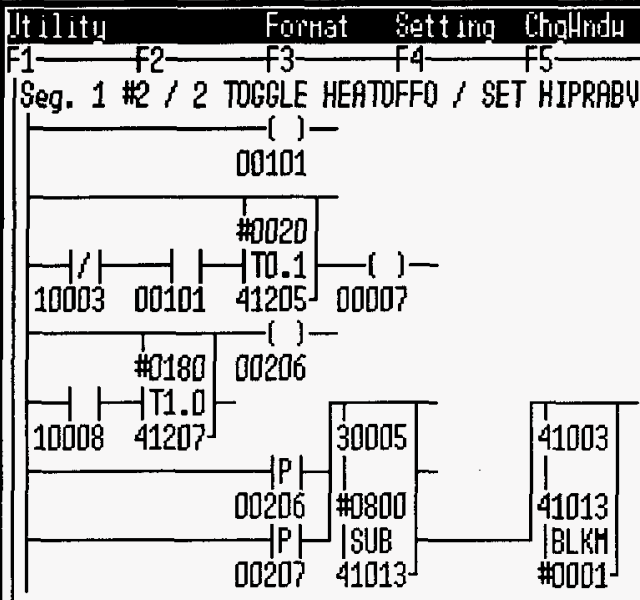

Reference Data

Fornat :Decinal

Offline

Range : 1 
WHC-SD-WM-CSDD-020, REV 0

\section{WEDSOFT}

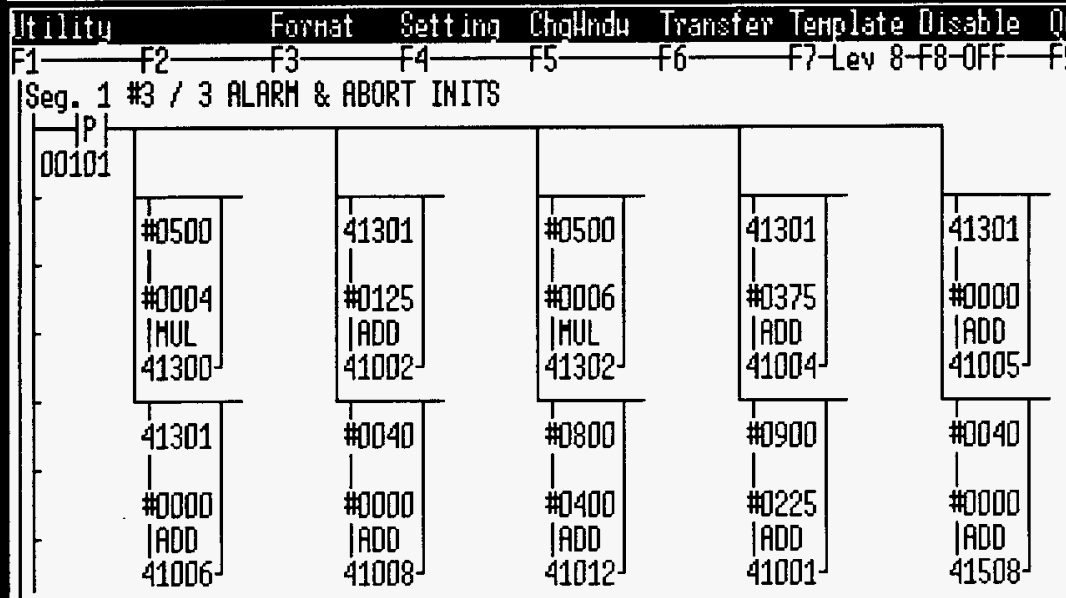

Reference Data

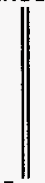

Format :Decimal

off lime

Range : 1 
WHC-SD-WM-CSDD-020, REV 0

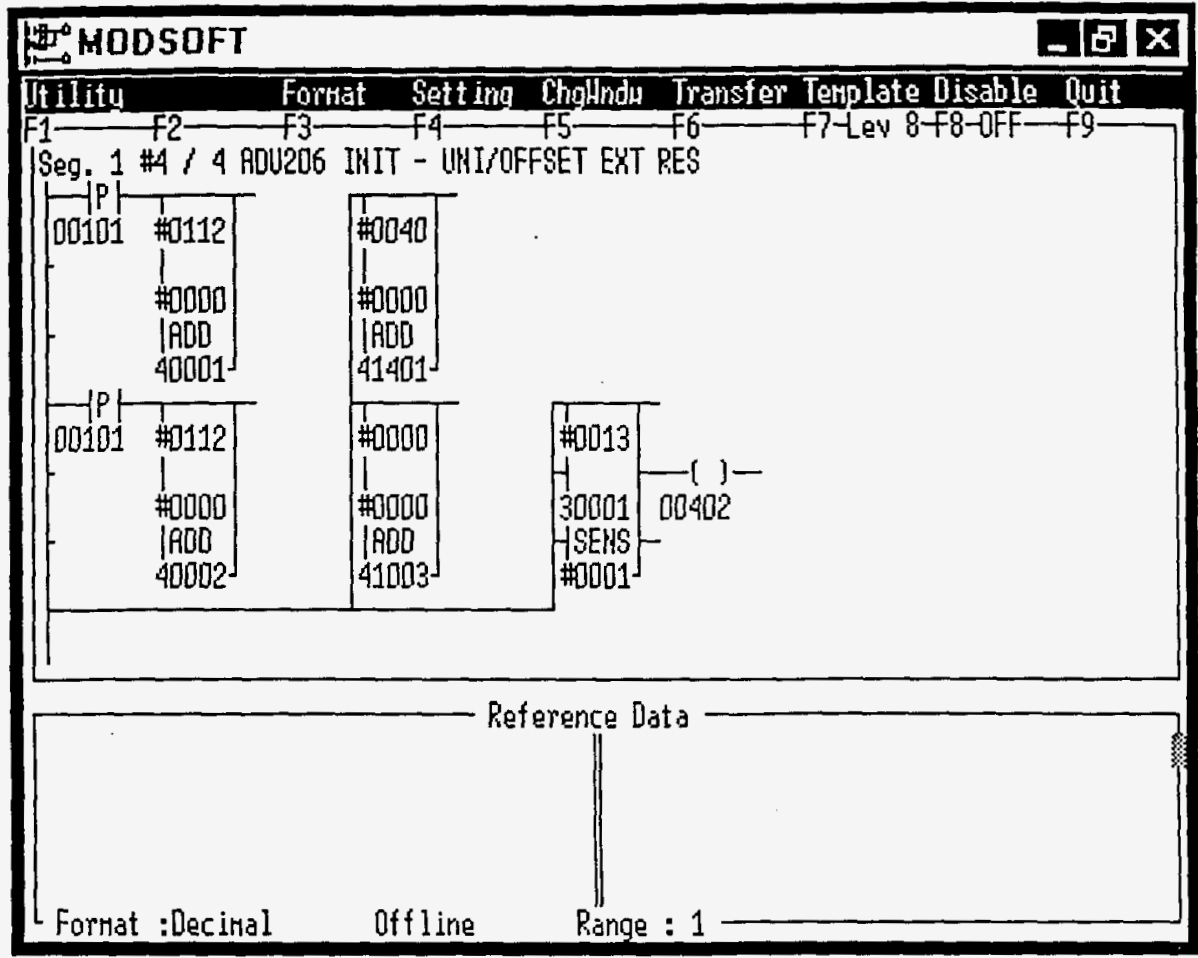




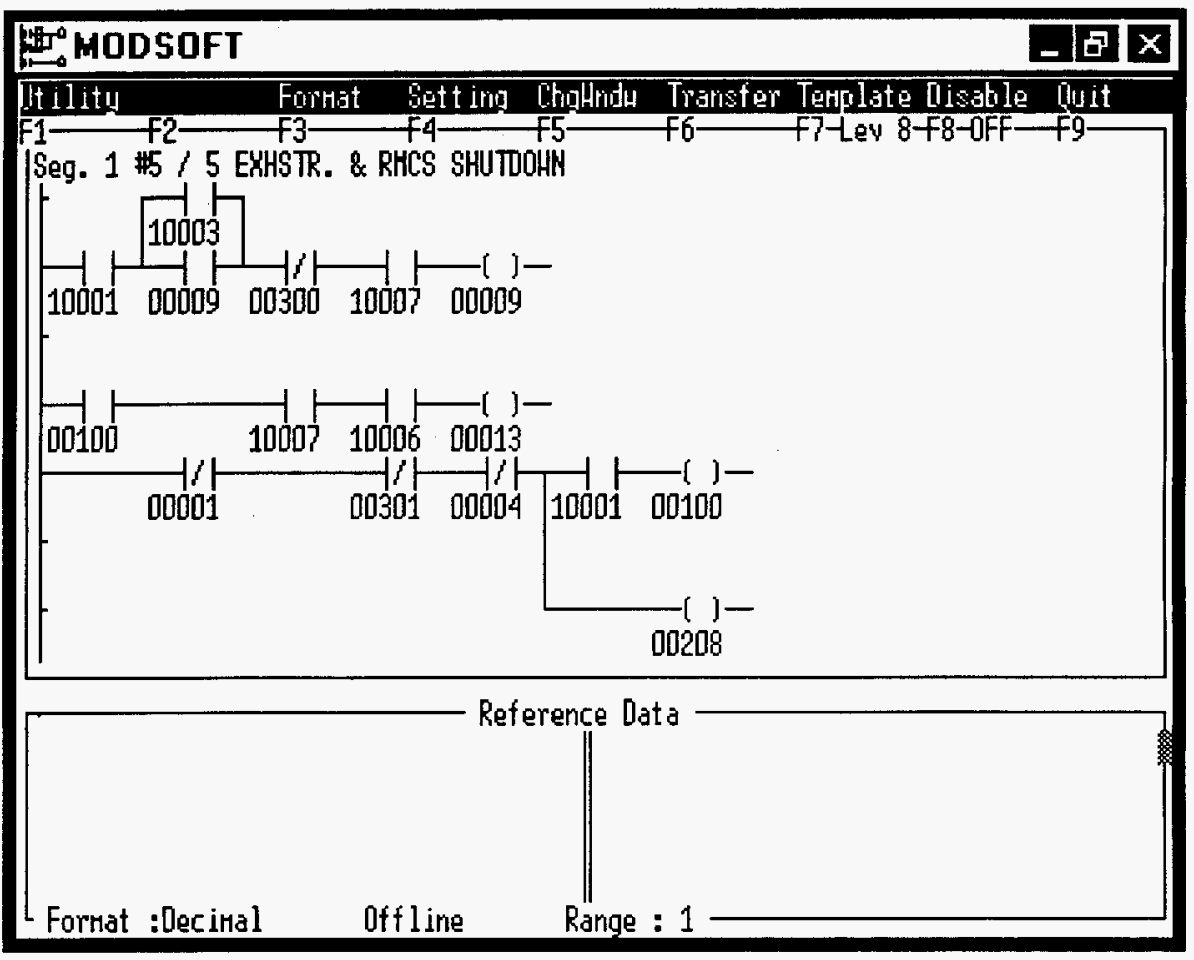


WHC-SD-WM-CSDD-020, REV 0

\section{WOFSOFT}

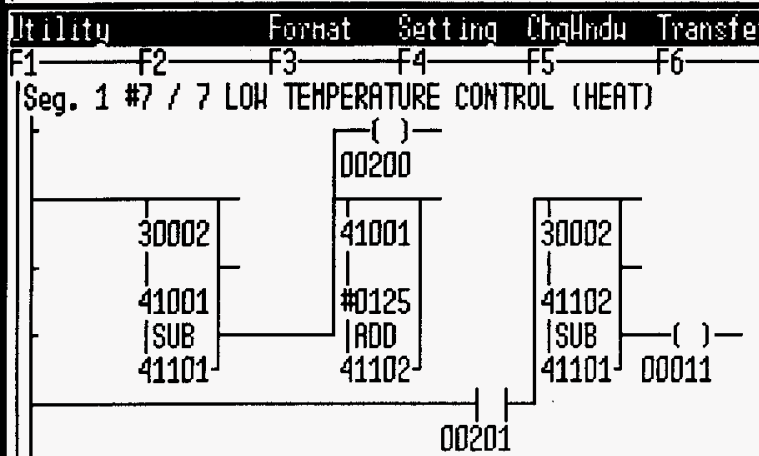

00200 00201

00011

Reference Data

Format :Decinal

off line

Range : 1 
WHC-SD-WM-CSDD-020, REV 0

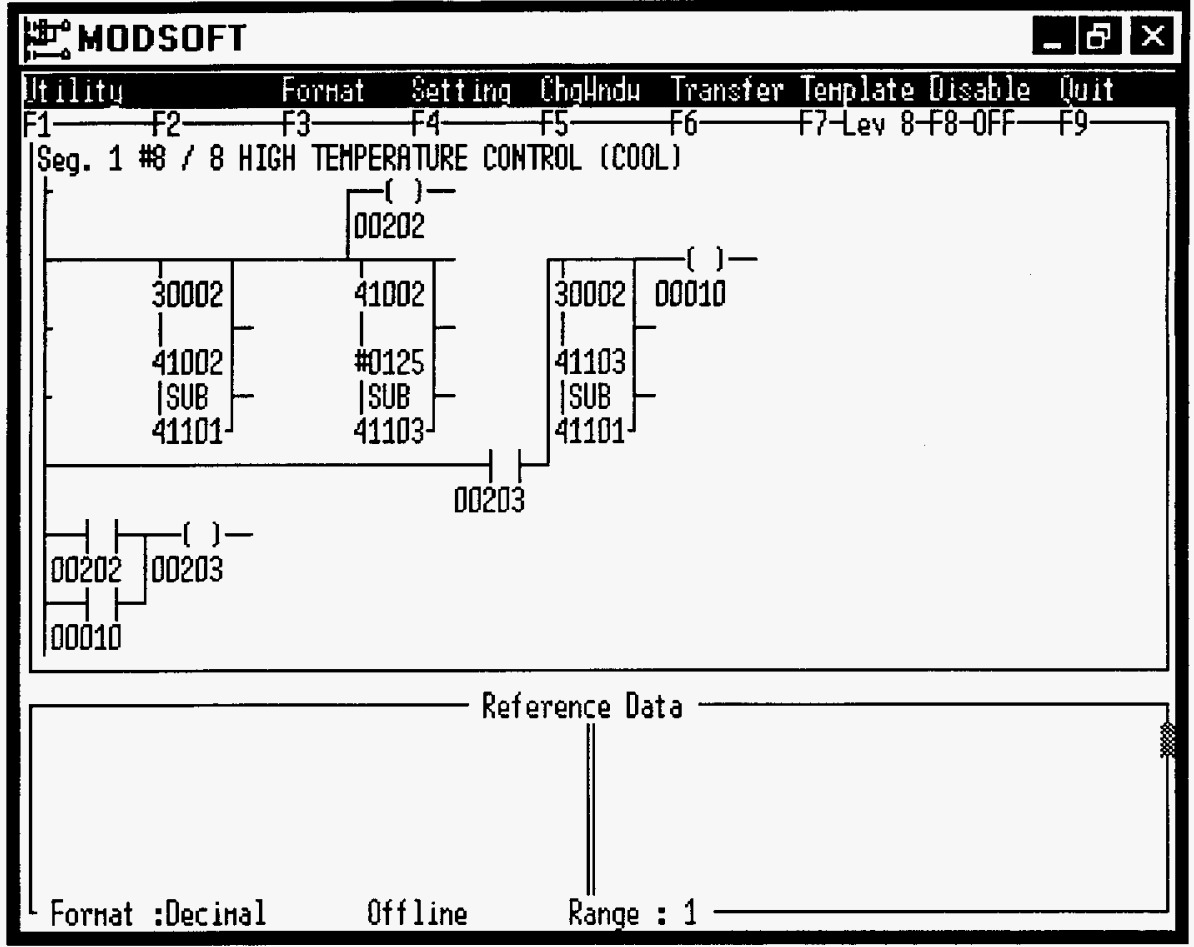


WHC-SD-WM-CSDD-020, REV 0

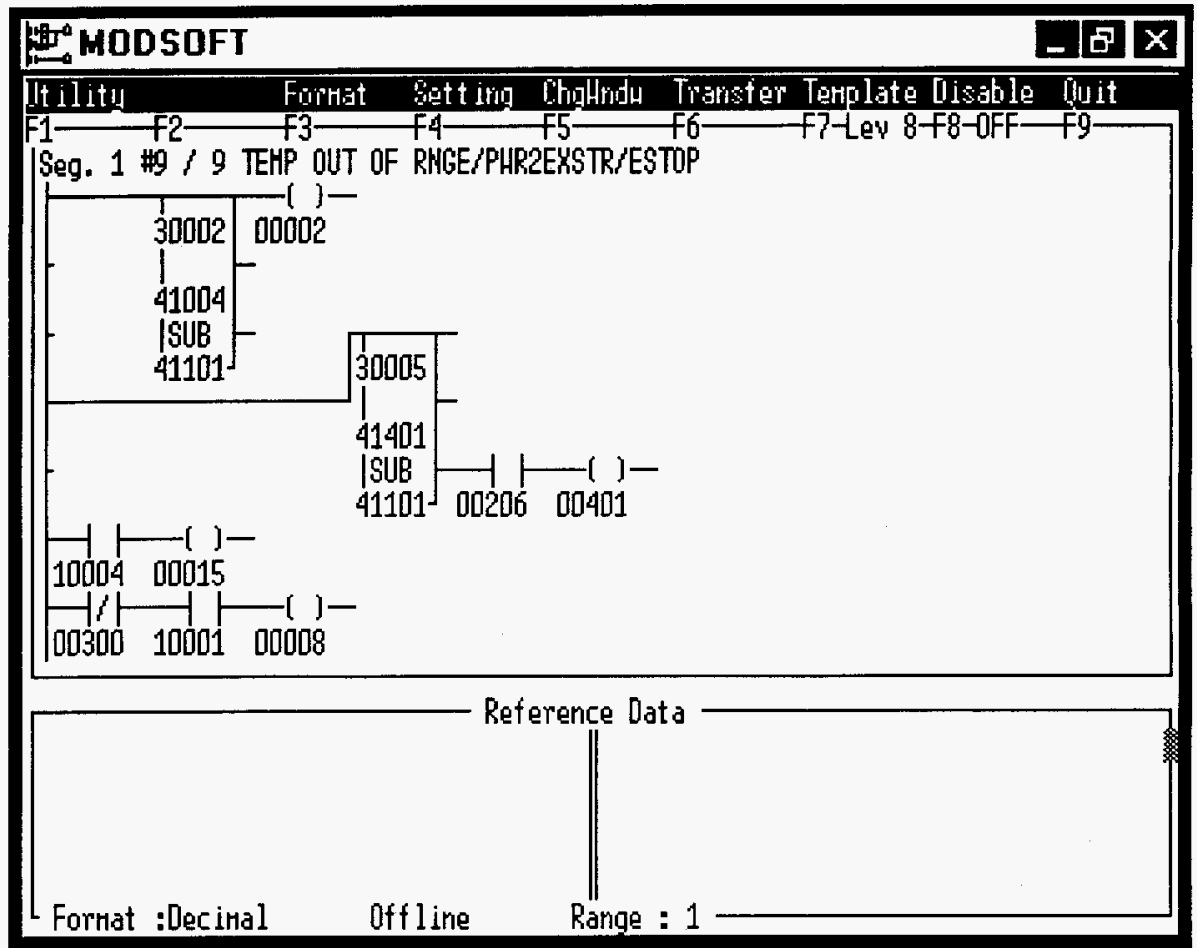

Page 43 


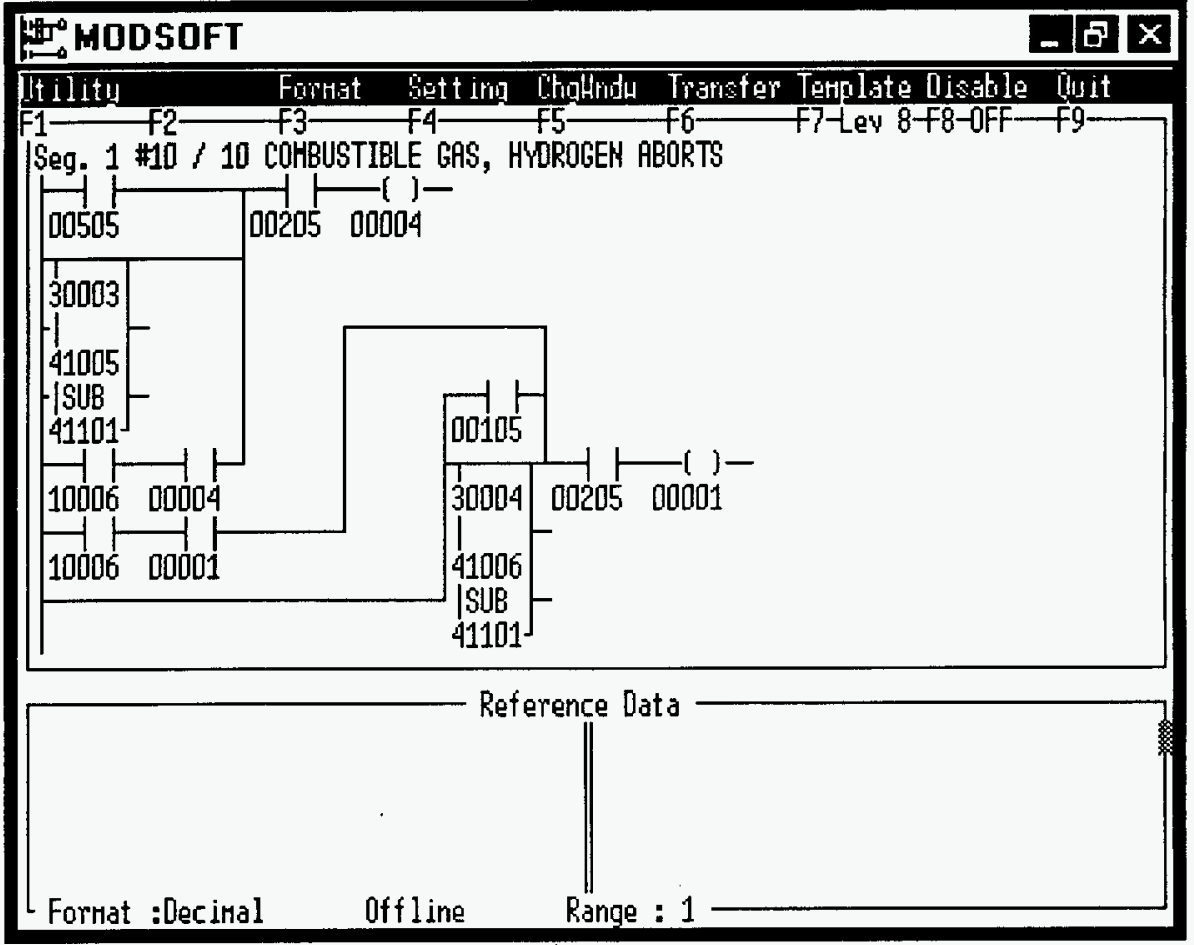


WHC-SD-WM-CSDD-020, REV 0

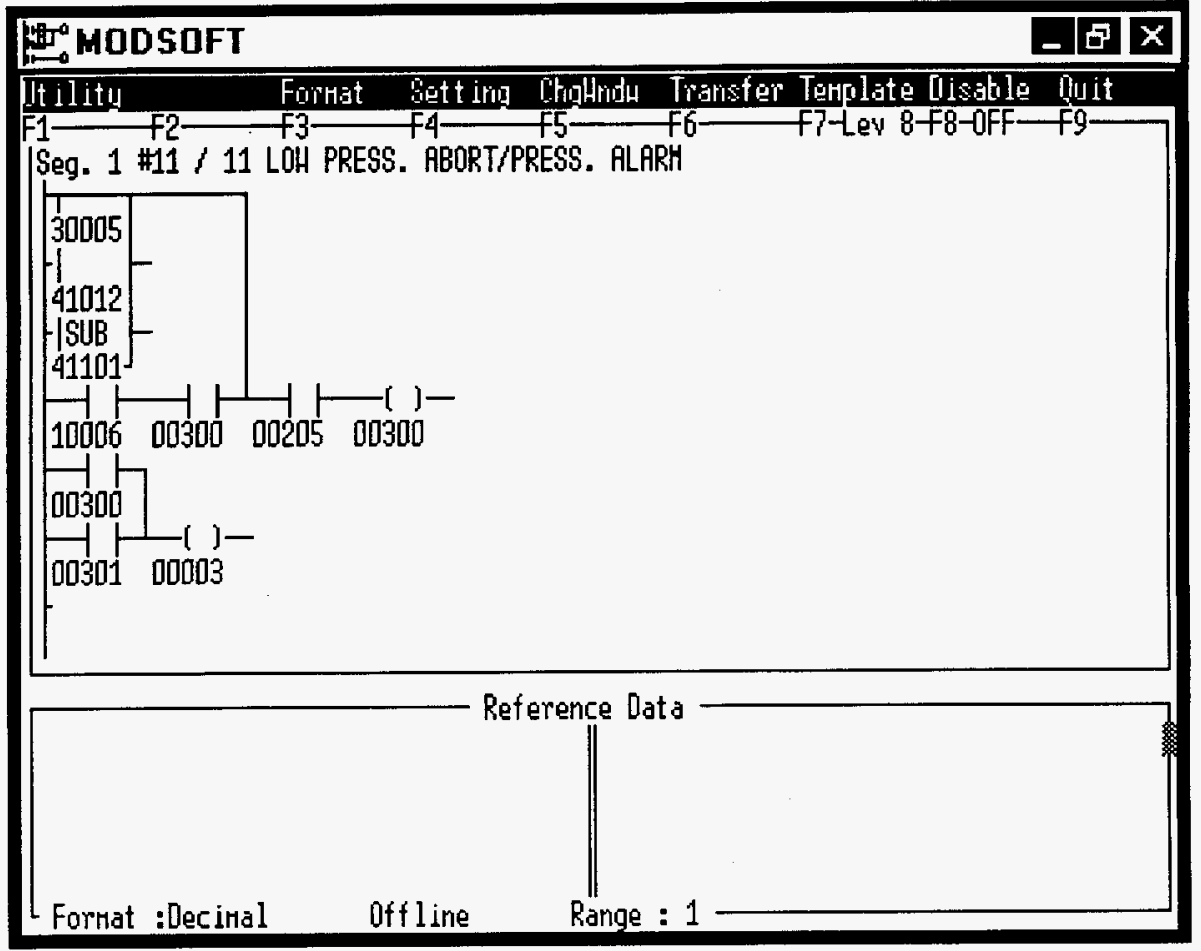

Page 45 


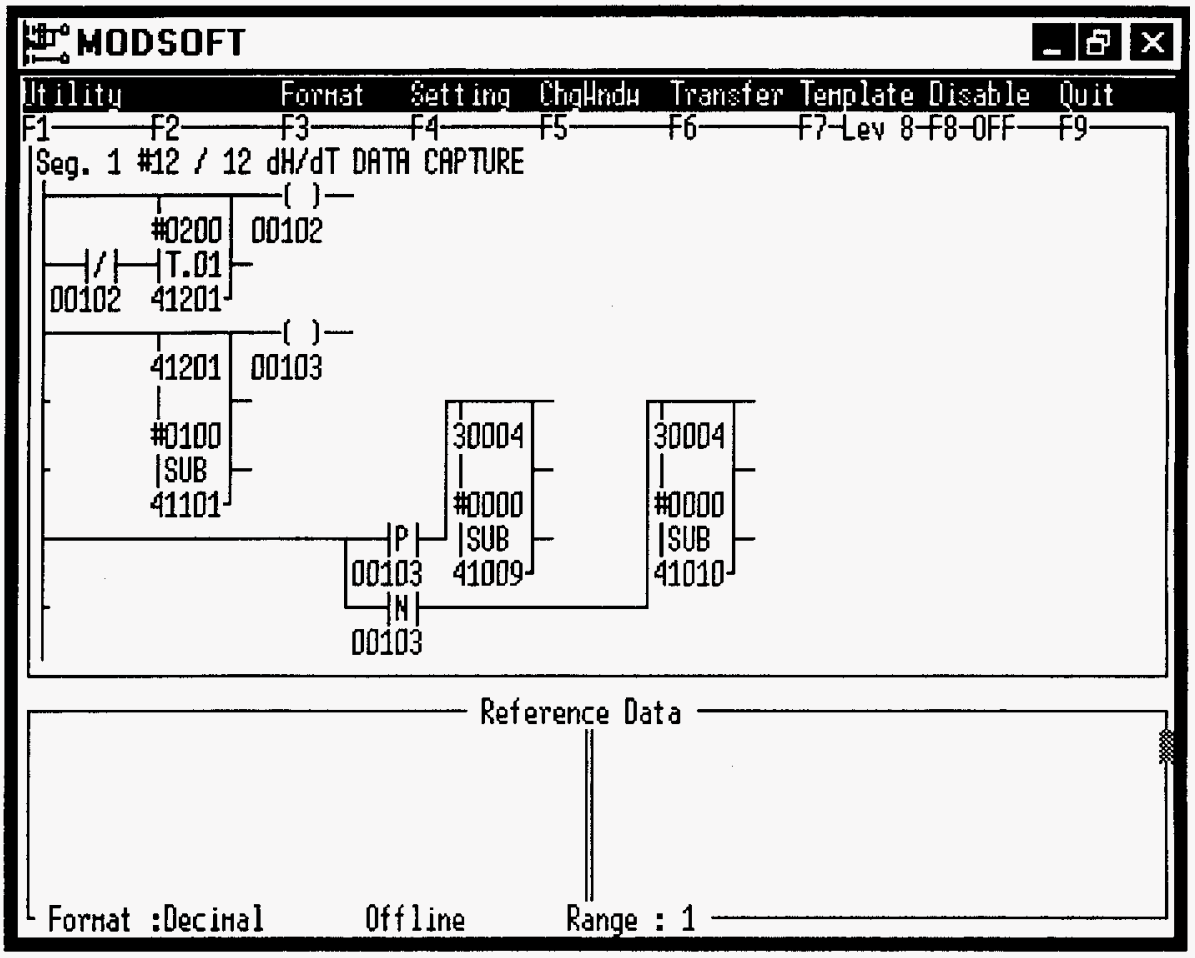




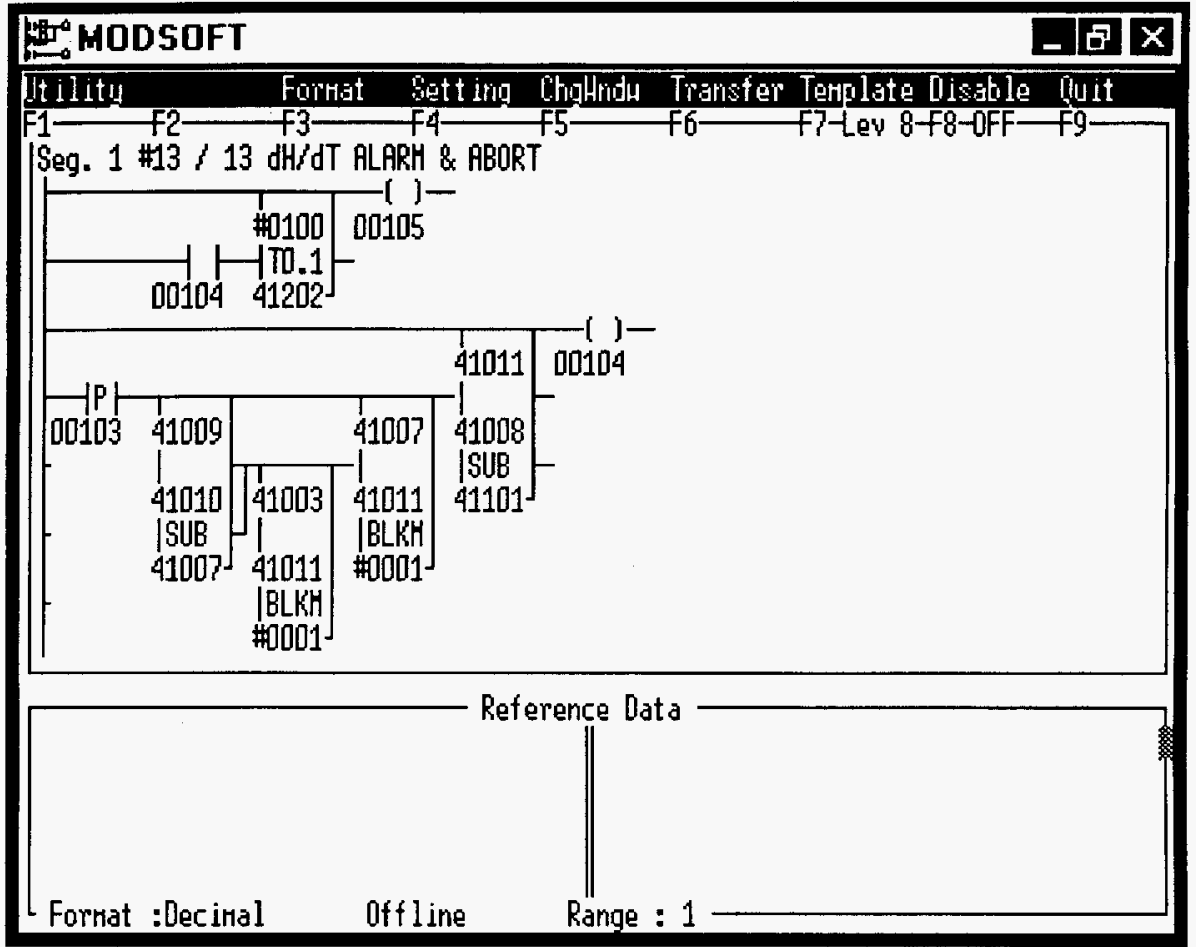




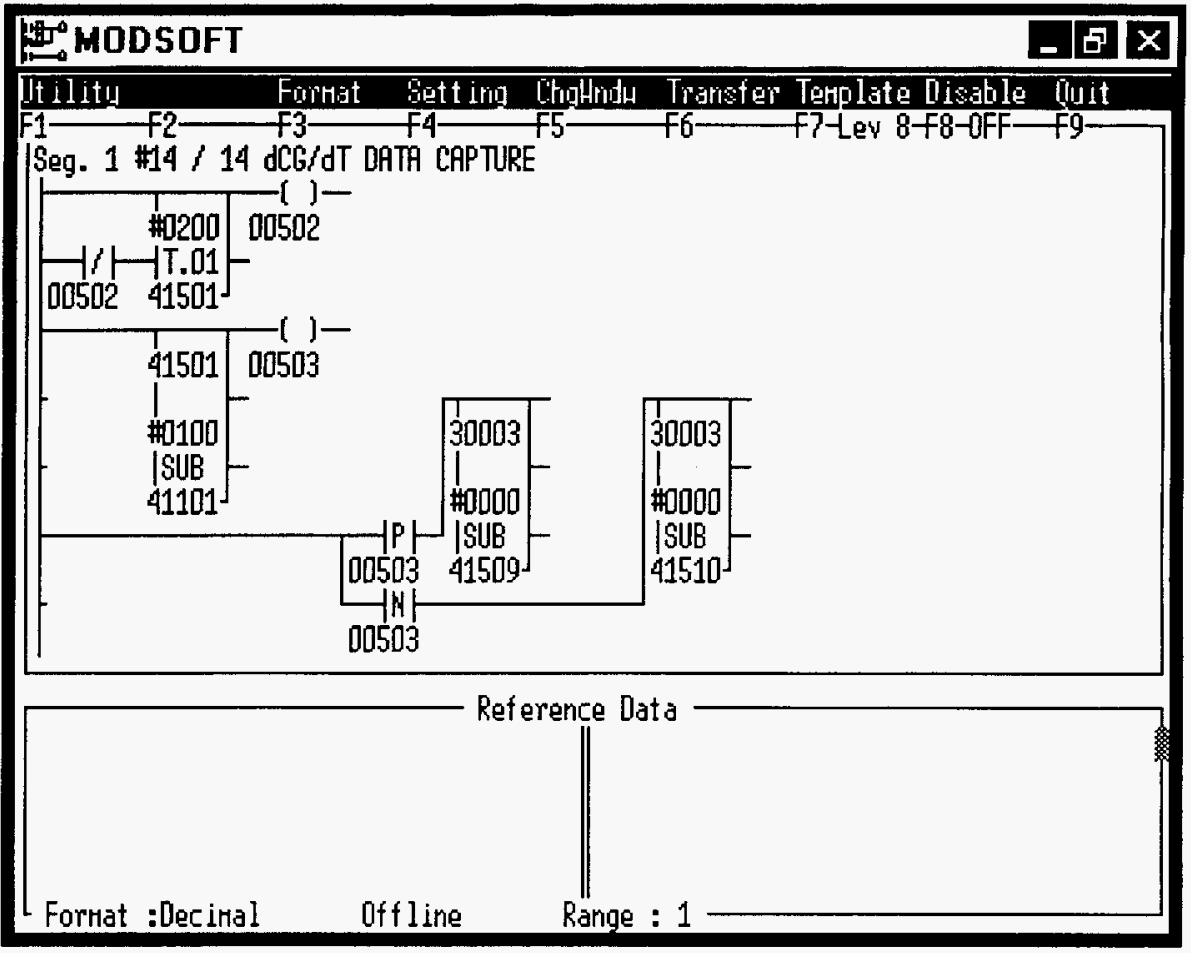




\section{PEODSOFT}

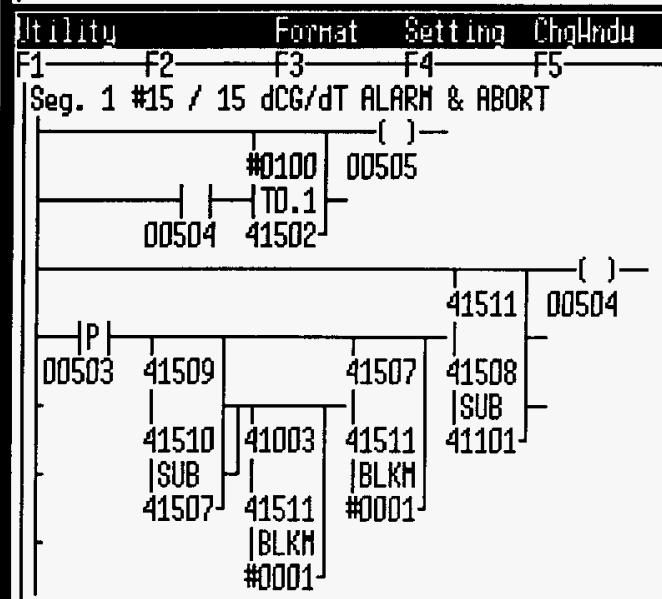

Format :Decinal

Reference Data

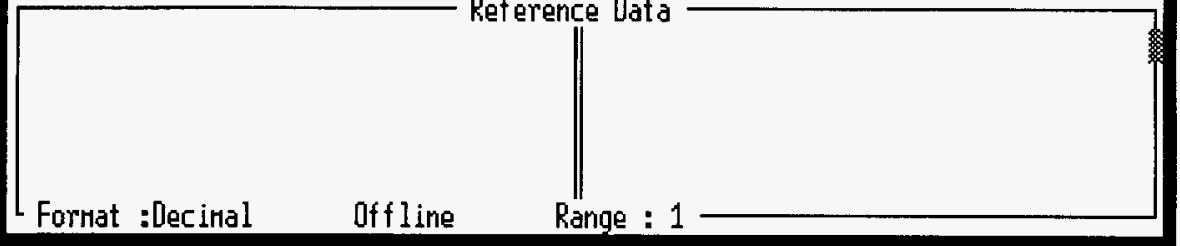

Transfor Tenplate [isable liuit 56 F7-Lev 8+8-0FF一 
WHC-SD-WM-CSDD-020, REV 0

\section{APPENDIX E}

Coil/Register Utilization Tables

Page 50 
WHC-SD-WM-CSDD-020, REV 0

FGTEI Ladder Logic - July 2, 1996

\section{Used OX References}

\begin{tabular}{|c|c|c|}
\hline & 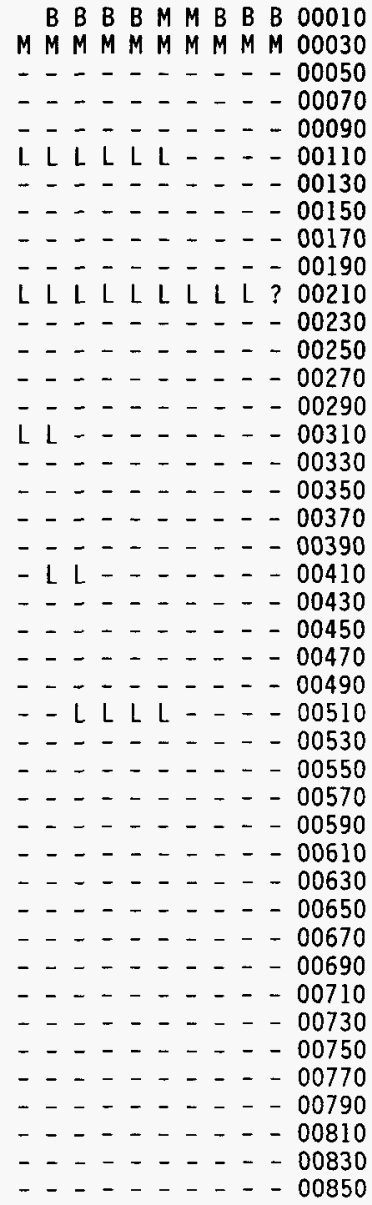 & \\
\hline
\end{tabular}

Page 51 
WHC-SD-WM-CSDD-020, REV 0

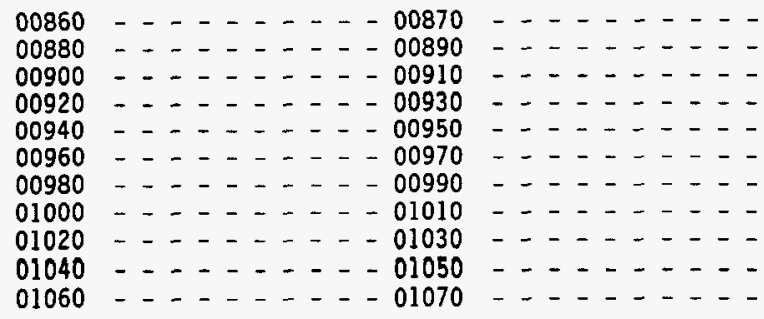

Key : UPPER CASE LETTER = DOCUMENTED; lower case letter $=$ un-documented $B=$ In both Logic and $I / 0$ $L=$ In Logic only

- = Available

$M=$ In $I / 0$ only

$?=$ Documented, but not used 
FGTEI Ladder Logic - July 2, 1996

\section{Used OX References}

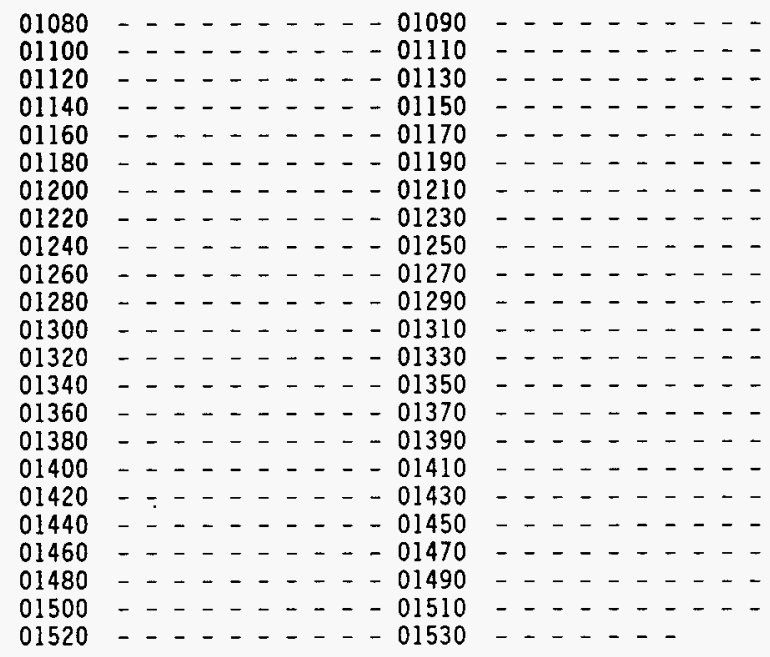


WHC-SD-WM-CSDD-020, REV 0

Key : UPPER CASE LETTER = DOCUMENTED; lower case letter $=$ un-documented

$B=$ In both Logic and I/0

$L=$ In Logic only

- = Available

$M=$ In $I / 0$ only 
FGTEI Ladder Logic - July 2, 1996

\section{Used 1X References}

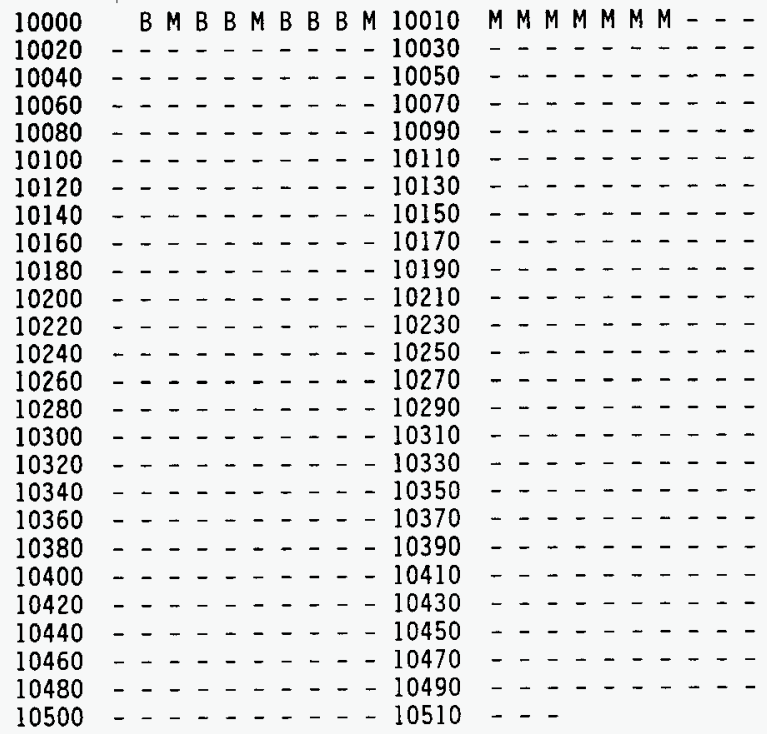


WHC-SD-WM-CSDD-020, REV 0

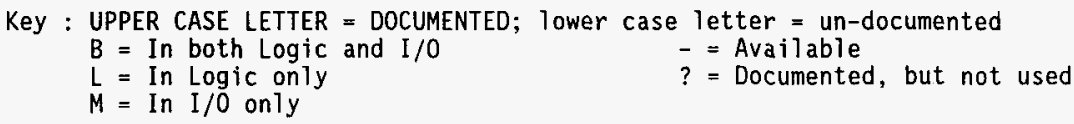


WHC-SD-WM-CSDD-020, REV 0

FGTEI Ladder Logic - July 2, 1996

Used 3X Registers

30000
30020

Page 57 
WHC-SD-WM-CSDD-020, REV 0

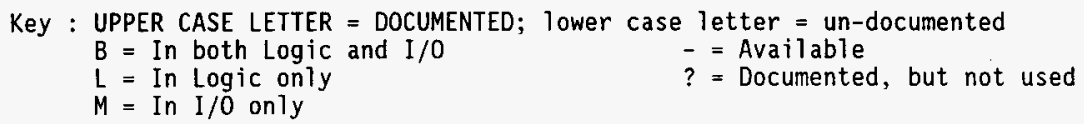


WHC-SD-WM-CSDD-020, REV 0

FGTEI Ladder Logic - July 2, 1996

Used 4X Registers

$$
\begin{aligned}
& 40000 \text { B B - - . } 40010 \ldots \\
& 40020 \text { - . . . - } 40030 \text { - . . . - } \\
& 40040 \ldots \ldots+\ldots 40050 \ldots \\
& 40060 \text { - . . . - } 40070 \text { - . - . - } \\
& 40080 \text { - } \ldots . . .-40090 \text { - } \ldots \text { - . . - } \\
& 40100 \text { - . . . . - } 40110 \text { - . . . - } \\
& 40120 \text { _...... - } 40130 \text { _. . . . } \\
& 40140 \text { - . . . - - } 40150 \text { - . - . - - } \\
& 40160 \text { _. . . . . } 40170 \ldots \\
& 40180 \text { - . - . - - } 40190 \text { - }-\ldots \\
& 40200 \text { - . . . . - } 40210 \text { - . - . - } \\
& 40220 \text { - - - - - } 40230 \text { - - - - - } \\
& 40240 \text { - . . . - - } 40250 \text { - . - . - } \\
& 40260 \text { _. . . . . } 40270 \text { _. . . . . } \\
& 40280 \text { - . . . - - } 40290 \text { - . . - - } \\
& 40300 \text { - . . . . } 40310 \ldots \\
& 40320 \text { - . . . . } 40330 \ldots \\
& 40340 \text { - . . . - - } 40350 \text { - . . - . } \\
& 40360 \text { - }-\ldots+\ldots-40370 \text { - }-\ldots \\
& 40380 \text { _. . . . - } 40390 \text { - . . . . } \\
& 40400 \text { - . . . . - } 40410 \text { - . . . - } \\
& 40420 \text { - . . . . } 40430 \text { - } \ldots \text { - . . } \\
& 40440 \text { - . . . . - } 40450 \text { - . . . . } \\
& 40460 \text { - . . . - }-40470 \text { - . . . - } \\
& 40480 \text {. . . . . - } 40490 \ldots \\
& 40500 \text { - . . . . } 400510 \ldots \\
& 40520 \text { - . . . - } 40530 \ldots \\
& 40540 \text { _. . . . . } 40550 \ldots \\
& 40560 \text { - . - . - - } 40570 \text { - . - . - } \\
& 40580 \text { - . . . . - } 40590 \ldots \\
& 40600 \text { - - - - - } 440610 \text { - . - - - } \\
& 40620 \text { - . . . . - } 40630 \text { - . . - . } \\
& 40640 \ldots \ldots+\ldots 40650 \ldots \\
& 40660 \text { - . . . . - } 40670 \text { - . . . - } \\
& 40680 \text { - . . - . - } 40690 \text { - . . - . } \\
& 40700 \text { - } \ldots \ldots+\ldots 40710 \ldots \ldots \\
& 40720 \text { - . - - - } 440730 \text { - . - . - } \\
& 40740 \text { - . . . . - } 40750 \ldots \\
& 40760 \text { - . . . . - } 40770 \text { - . . . - } \\
& 40780 \text { - . . . . } 40790 \ldots \\
& 40800 \text { - . . . . - } 40810 \ldots \\
& 40820 \text { - } 40840 \text { - }
\end{aligned}
$$

Page 59 
WHC-SD-WM-CSDD-020, REV 0

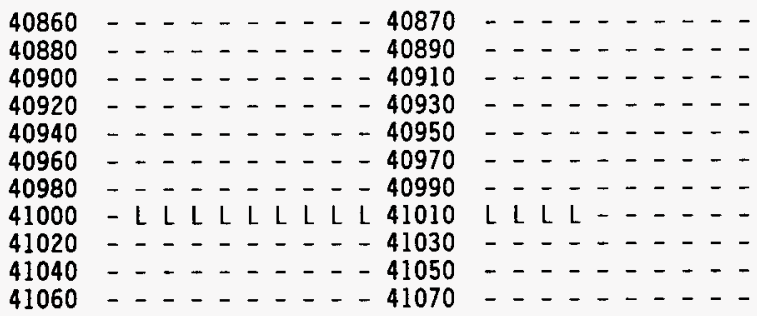

Key : UPPER CASE LETTER = DOCUMENTED; lower case letter = un-documented

$B=$ In both Logic and $I / 0$

$L=$ In Logic only

- = Available

$M=$ In $\mathrm{I} / 0$ only

$?=$ Documented, but not used 
FGTEI Ladder Logic - July 2, 1996

\section{Used 4X Registers}

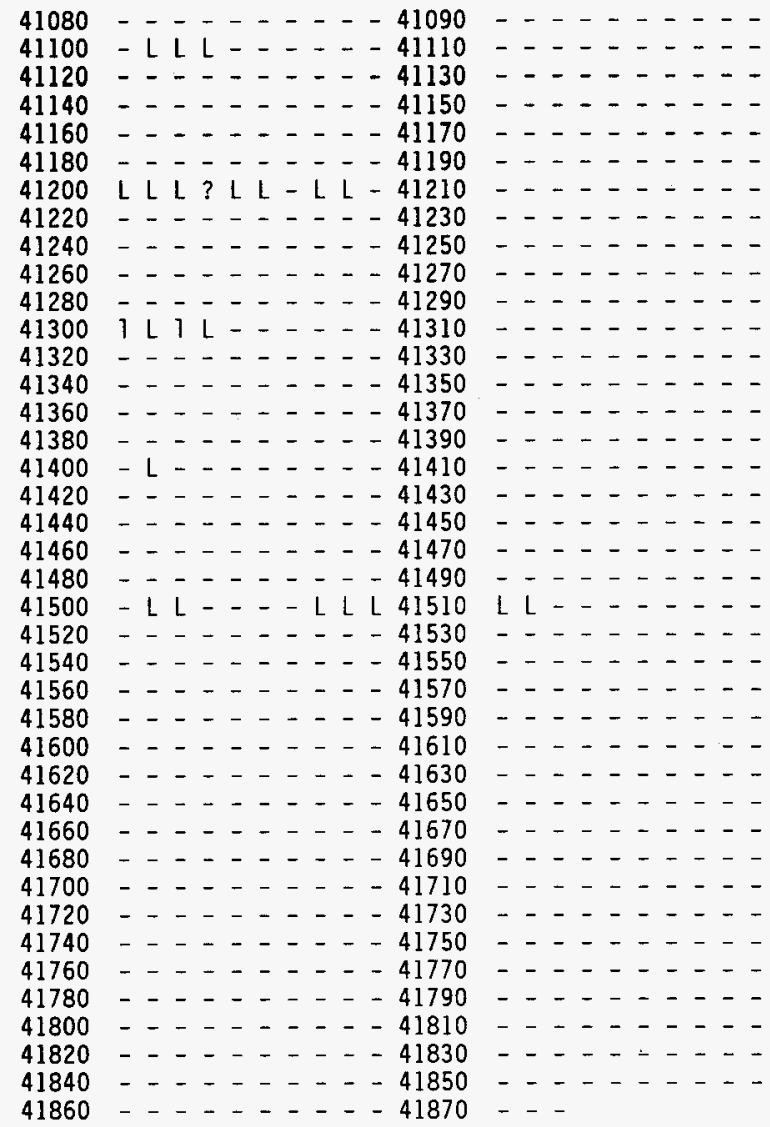


WHC-SD-WM-CSDD-020, REV 0

Key : UPPER CASE LETTER $=$ DOCUMENTED; lower case letter $=$ un-documented

$B=$ In both Logic and $\mathrm{I} / 0$

$L=$ In Logic only

- = Available

$M=$ In $1 / 0$ only

41864 Timer Register

41865 - 41872 Time/Date Register

Page 62 
WHC-SD-WM-CSDD-020, REV O

APPENDIX F

ADU206 Control Register Reference

Page 63 


\section{ADU 206 40XXX Control Register Quick Reference}

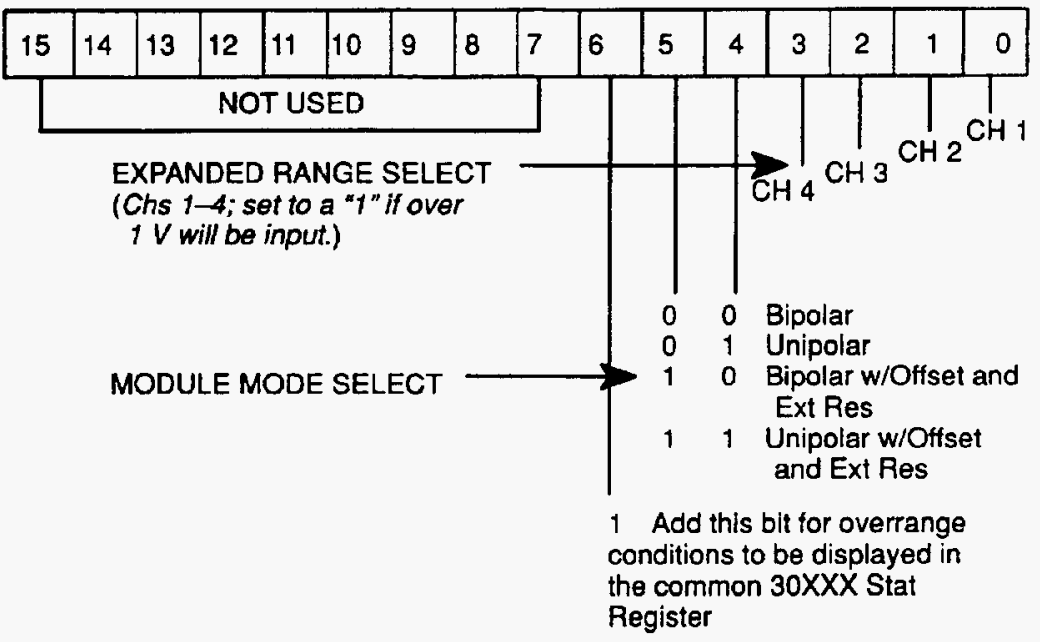

EXAMPLE:

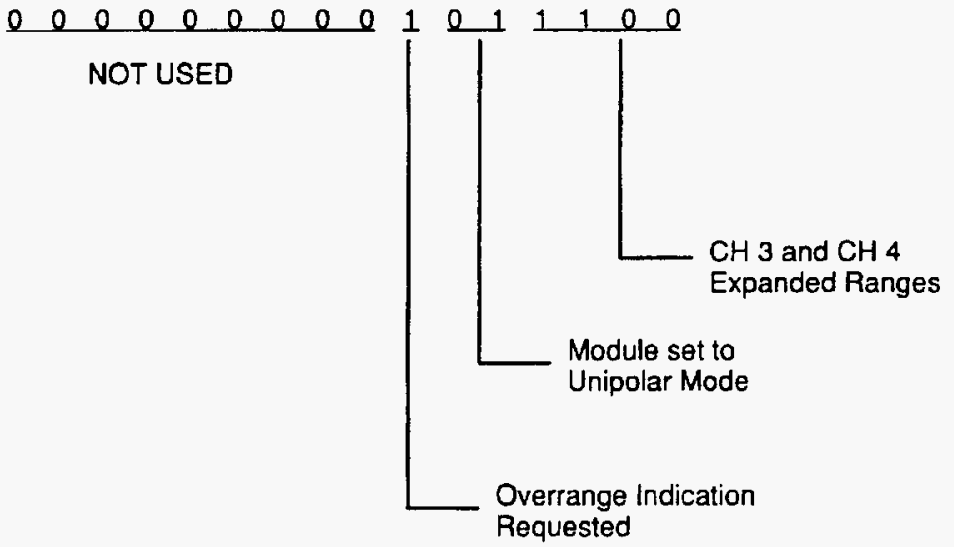

Page 64 